\title{
Emergent Properties of the Metaphase Spindle
}

\author{
Simone Reber ${ }^{1,2}$ and Anthony A. Hyman ${ }^{1}$ \\ ${ }^{1}$ Max Planck Institute of Molecular Cell Biology and Genetics, 01307 Dresden, Germany \\ ${ }^{2}$ Integrative Research Institute (IRI) for the Life Sciences, Humboldt-Universität zu Berlin, \\ 10115 Berlin, Germany \\ Correspondence: hyman@mpi-cbg.de
}

\begin{abstract}
A metaphase spindle is a complex structure consisting of microtubules and a myriad of different proteins that modulate microtubule dynamics together with chromatin and kinetochores. A decade ago, a full description of spindle formation and function seemed a lofty goal. Here, we describe how work in the last 10 years combining cataloging of spindle components, the characterization of their biochemical activities using single-molecule techniques, and theory have advanced our knowledge. Taken together, these advances suggest that a full understanding of spindle assembly and function may soon be possible.
\end{abstract}

B ecause of its prominent geometry, the mitotic spindle was identified under the light microscope as early as the 19th century (Flemming 1882). The central function of this structure, which has fascinated cell biologists ever since, is to accurately segregate chromosomes into two identical sets. The dynamic properties of spindle microtubules are modulated by accessory proteins known as microtubule-associated proteins (MAPs) and motors. These proteins modulate every aspect of a microtubule's life. They help microtubules nucleate, grow, shrink, pause, and switch between all of these states. In recent years, the biochemical activities of these individual proteins have been extensively studied. The advent of single-molecule techniques has allowed unprecedented insight into their detailed activities and the relationship between these activities and the microtubule lattice. However, one question remains. How do spindle morphology and function emerge through the dynamic activities of hundreds of proteins?

"Emergence" describes the way complex properties and patterns of a system arise out of a multiplicity of simple interactions. Examples include the generation of an infinite variety of six-sided snowflakes from frozen water in snow (Libbrecht 2005). Similarly, "flocking," the coordinated motion of animals observed in bird flocks, fish schools, or insects swarms, is considered an emergent behavior (Berdahl et al. 2013). In physics, emergent behaviors are commonly studied to describe complex systems. Physics thus provides a framework for relating the microscopic properties of individual molecules to the macroscopic properties of materials. In this review, we first discuss progress in our understanding of the biochemistry of individual molecules required for modulating microtubule dynamics with a focus on recent quantitative data from biophysical and biochemical

Editors: Mitsuhiro Yanagida, Anthony A. Hyman, and Jonathon Pines

Additional Perspectives on Mitosis available at www.cshperspectives.org

Copyright (C) 2015 Cold Spring Harbor Laboratory Press; all rights reserved; doi: 10.1101/cshperspect.a015784

Cite this article as Cold Spring Harb Perspect Biol 2015;7:a015784 
reconstitution assays. We highlight what we still need to understand to link molecular and collective function. We then discuss theoretical approaches, which integrate molecular details and help to achieve a systems understanding of spindle organization and function. Finally, we discuss forthcoming concepts of cellular scaling, which assure that the spindle adapts its size to the size of the cell.

\section{KEY PLAYERS OF SPINDLE ORGANIZATION}

The metaphase spindle is a bipolar array of microtubules assembled from dimeric $\alpha \beta$-tubulin subunits that polymerize in a head-to-tail fashion into polar filaments with $\beta$-tubulin facing the plus end and $\alpha$-tubulin the minus end (Mitchison 1993). Approximately 13 protofilaments associate laterally to form a dynamic microtubule. The de novo formation of microtubules is termed nucleation, which gives rise to a dynamic microtubule. Microtubule dynamic instability can empirically be described by four parameters: (1) the microtubule polymerization velocity, (2) the depolymerization velocity, (3) the catastrophe frequency when microtubules switch from growth to shrinkage, and (4) the rescue frequency when microtubules switch from shrinkage to growth (Mitchison and Kirschner 1984). Microtubule polymerization (Dogterom and Yurke 1997) and depolymerization (Lombillo et al. 1995) produce mechanical forces. In addition, microtubules are subject to passive spindle forces such as elasticity and molecular friction (Dumont and Mitchison 2009b; Itabashi et al. 2009; Shimamoto et al. 2011) and to active force generated by motor proteins, such as kinesins and cytoplasmic dynein, which use the energy from ATP hydrolysis to step along microtubules (Gennerich and Vale 2009). Microtubule nucleation and dynamics as well as spindle forces are controlled by a set of regulatory proteins that specifically interact with distinct regions of the microtubule.

\section{MICROTUBULE NUCLEATION}

The centrosome is the classic organelle associated with microtubule nucleation. The $\gamma$-tubu- lin small complex $(\boldsymbol{\gamma}$-TuSC) is the conserved, functional unit of the centrosome essential for microtubule nucleation. Multiple $\gamma$-TuSCs assemble into a $\gamma$-tubulin ring complex $(\boldsymbol{\gamma}$-TuRC) in the presence of several other associated proteins (Fig. 1) (Keating and Borisy 2000; Moritz et al. 2000; Wiese and Zheng 2000, 2006; Kollman et al. 2010). The favored model for microtubule nucleation is the template model, in which $\gamma$-tubulin assembles into a ring of 13 molecules that form a template for the nucleation of microtubules with 13 tubulin protofilaments (Moritz et al. 1995; Zheng et al. 1995; Pereira and Schiebel 1997). This model is supported by in vitro findings showing that purified $\gamma$-TuRC caps microtubule minus ends (Zheng et al. 1995; Moritz et al. 2000), and that the purified yeast $\gamma$-TuSC assembles into spirallike filaments of $13 \gamma$-tubulin molecules per turn (Kollman et al. 2010).

Although centrosomes are considered the classic organelle for microtubule nucleation, spindles readily form in the absence of centrosomes. Plant cell mitosis (De Mey et al. 1982; Zhang and Dawe 2011) and animal egg meiosis occur without centrosomes (Manandhar et al. 2005; Dumont and Desai 2012). In addition, different experimental approaches show that animal cell mitosis can occur normally after centrosomes have been removed (Khodjakov et al. 2000; Hinchcliffe et al. 2001; Megraw et al. 2001; Basto et al. 2006; Mahoney et al. 2006). This implies that nucleation of spindle microtubules does not always rely on centrosomes. Indeed, seminal work in Xenopus egg extracts revealed that chromatin can promote microtubule nucleation (Heald et al. 1996). The spatial cue necessary to nucleate microtubules around chromatin is mediated by a diffusion-limited RanGTP gradient (Fig. 1) (Carazo-Salas et al. 1999; 2001; Kaláb et al. 1999; Ohba et al. 1999; Nachury et al. 2001). Ran is a small GTPase that drives nucleocytoplasmic transport during interphase, whereby the high concentration of the guanosine triphosphate (GTP)-bound form of Ran in the nucleus allows the release of newly imported proteins from their binding to importins (Clarke 2008). Similarly, during mitosis, a high-RanGTP gradient, centered around chro- 


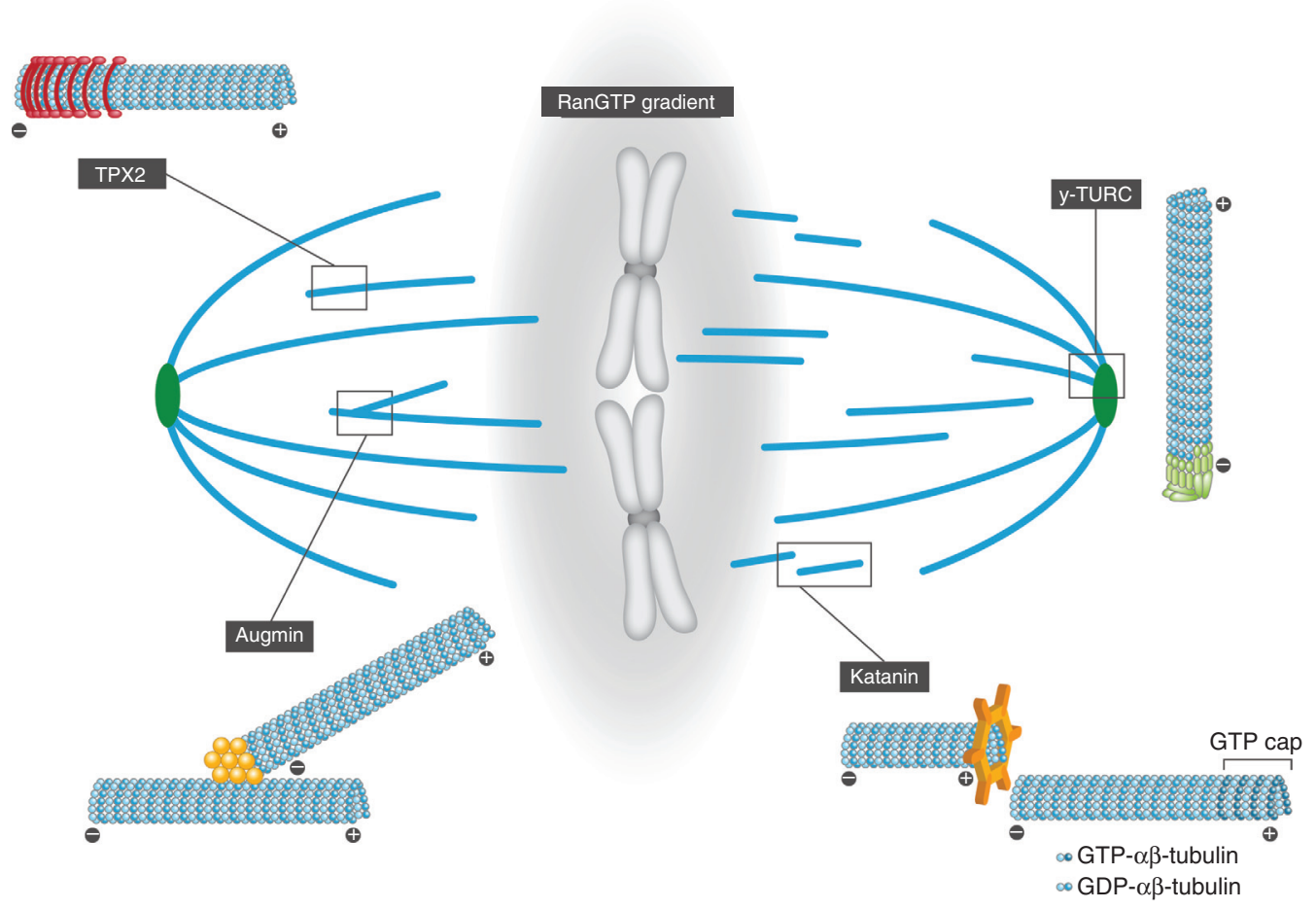

Figure 1. Microtubule nucleation, stabilization, and amplification. The metaphase spindle is a complex structure consisting of microtubules (blue) that nucleate from centrosomes (green) and chromatin (gray). A central centrosomal component is the $\gamma$-tubulin ring complex $(\gamma$-TuRC), which templates the nucleation of microtubules. The spatial cue necessary to nucleate microtubules around chromatin is mediated by a diffusion-limited RanGTP gradient, the first identified direct effector of which is TPX2. The eight-subunit complex augmin nucleates microtubules parallel to existing microtubules, while katanin severs and disassembles microtubules. GDP, Guanosine diphosphate; GTP, guanosine triphosphate.

matin, releases putative spindle assembly factors (SAFs) from importins, thereby enabling the SAFs to perform their function in spindle assembly. The first identified direct effector of RanGTP in spindle assembly is TPX2 (Fig. 1) (Gruss et al. 2001, 2002). Removal of TPX2 function abolishes spindle assembly (Wittmann et al. 2000; Gruss et al. 2001, 2002; Tulu et al. 2006; Greenan et al. 2010). Although TPX2 induces microtubule nucleation when added to Xenopus egg extracts (Gruss et al. 2001) and promotes the assembly of microtubules from pure tubulin in solution (Schatz et al. 2003; Brunet et al. 2004), it remains to be shown whether TPX2 is a true microtubule nucleator. In addition, TPX2 is an activator of the mitotic kinase Aurora A (Kufer et al. 2002; Tsai et al. 2003; Eyers and Maller 2004; Ozlü et al. 2005). Work in HeLa cells suggests that the chromatin nucleation capacity of TPX2 is mediated through $\mathrm{Au}-$ rora A activation and not by TPX2 directly (Bird and Hymann 2008). Thus, the current model is that the Ran gradient induces downstream gradients, such as an Aurora A phosphorylation gradient, and thereby effects not only microtubule nucleation but also microtubule dynamics and motor activities (Gruss and Vernos 2004).

There is direct evidence for a diffusion-limited RanGTP gradient surrounding chromosomes in mitotic somatic cells (Kaláb et al. 2006). Although chromatin-based microtubule nucleation has been visualized in mammalian cells (Khodjakov et al. 2003), chromatin-dependent nucleation is not essential for spindle bipolarity during human cell mitosis when centrosomes are present (Kaláb et al. 2006; Bird and 
Hymann 2008). Thus, the relative contribution of microtubule nucleation by the RanGTP gradient appears to be organism- and cell-typespecific (Sato and Toda 2007). Although this is essential for anastral spindle assembly during female meiosis, it might just provide a kinetic advantage during the early stages of spindle assembly in primarily centrosome-driven somatic cells. Notably, in both somatic cells and Xenopus egg extracts, the steepness of the Ran-regulated gradient seems to correlate with spindle size (Kaláb et al. 2002, 2006). Whether the steepness of the Ran gradient or of its effectors actively determines spindle size in these systems is still an open question.

\section{MICROTUBULE AMPLIFICATION}

One open question is whether microtubule nucleation by centrosomes and/or the RanGTP pathway can generate a sufficient number of microtubules to account for the total spindle mass. There is experimental evidence that microtubule minus ends are spread throughout the spindle (Burbank et al. 2006; Mahoney et al. 2006; Yang et al. 2007; Brugués et al. 2012), indicative of microtubule nucleation happening within the spindle body. Indeed, the eight-subunit complex augmin (Fig. 1) has been shown to recruit $\gamma$-TuRC to the side of pre-existing microtubules and to initiate the nucleation of new microtubules (Goshima et al. 2008; Lawo et al. 2009). This is consistent with the idea of a nucleator that becomes activated once it binds to a microtubule as a kinetic model of autocatalytic microtubule production (Clausen and Ribbeck 2007). Although depletion of augmin by RNAi decreases microtubule density within the spindle (Goshima et al. 2007, 2008; Zhu et al. 2008; Lawo et al. 2009; Uehara et al. 2009; Uehara and Goshima 2010; Petry et al. 2011; Hotta et al. 2012; Nakaoka et al. 2012), the contribution of microtubule amplification seems to differ significantly in different cell types. For example, augmin genes cannot be found in the Caenorhabditis elegans genome, making the worm a system in which centrosomes play the dominant role in generating spindle microtubules (Hamill et al. 2002). In Drosophila oocytes, aug- min is dispensable for chromatin-driven assembly of bulk spindle microtubules (Colombié et al. 2013), whereas, in Drosophila S2 cells, augmin depletion significantly reduces microtubule density in spindles (Goshima et al. 2007, 2008). Spindles formed in augmin-depleted Xenopus egg extracts show a temporal delay in acentrosomal spindle formation. In the presence of centrosomes, however, defects in spindle morphology are modest (Petry et al. 2011).

So far, it is unclear how chromatin-dependent microtubule nucleation and microtubuledependent microtubule amplification are interregulated, if at all. A recent study now shows that RanGTP stimulates augmin-dependent microtubule amplification, which is dependent on TPX2 (Petry et al. 2013), thereby linking the two pathways. As augmin nucleates microtubules parallel to existing microtubules, and in this way preserves microtubule polarity (Kamasaki et al. 2013; Petry et al. 2013), this pathway might be important to amplify and stabilize preformed structures once bipolarity is established. Still, the exact mechanism by which RanGTP spatially and temporally controls de novo nucleation on the one hand and microtubule-dependent microtubule nucleation on the other remains to be shown.

\section{MICROTUBULE SEVERING}

Although it is clear that regulators of microtubule nucleation, amplification, and growth influence microtubule mass, the cellular consequences of microtubule severing are more complex. Although in vitro severing leads to the complete loss of a microtubule, the in vivo consequences of severing include microtubule amplification, the release of microtubules from nucleation sites, and complete microtubule disassembly (Srayko et al. 2000; McNally et al. 2006; Yu et al 2008; Loughlin et al. 2011). Active microtubule severing was first described as an M phase-specific activity (Vale 1991) and subsequently attributed to the protein katanin (Fig. 1) (McNally and Vale 1993). Katanin is a heterodimeric protein, composed of a targeting subunit ( p80) and an enzymatic subunit (p60), with an ATPase activity that severs and disas- 
sembles microtubules (Hartman et al. 1998). Together with spastin and fidgetin, katanin represents an AAA (ATPases associated with diverse cellular activities) subfamily with a highly conserved AAA domain at their carboxyl terminus. In C. elegans, the loss of katanin results in fewer but longer spindle microtubules (Srayko et al. 2000, 2006; McNally et al. 2006). In contrast, Dm katanin was shown to cut stabilized microtubule ends, and thus provide a substrate for kinesin-13-dependent depolymerization (Buster et al. 2002; Zhang et al. 2011). In the two closely related frogs, Xenopus laevis and tropicalis, katanin was shown to contribute to setting spindle length by differentially accelerating microtubule depolymerization at the spindle poles (see below) (Loughlin et al. 2011).

Although some studies put severing proteins in the context of depolymerases, severing proteins - if at all-are only weak depolymerases (Díaz-Valencia et al. 2011; Zhang et al. 2011) when compared to classic ones such as mitotic centromere-associated kinesin (MCAK). What remains to be understood? Maybe the most important aspect on the molecular level is to understand how severing enzymes identify the regions of microtubules on which they act. Several lines of evidence suggest posttranslational modifications of tubulin to enhance severing activity (Sharma et al. 2007; Lacroix et al. 2010). Although it is clear that severing has an influence on microtubule dynamics, it remains unclear in what way it affects microtubule mass and, thus, spindle organization globally. Severing could induce microtubule depolymerization and thereby increase turnover. Alternatively, severing could create new templates for microtubule growth and thereby influence the effective nucleation rates. This might depend on the cellular context the newly cut microtubule ends encounter and whether they shrink or grow.

\section{MICROTUBULE DYNAMICS}

In vitro experiments with purified tubulin show that both microtubule ends exhibit dynamic instability (Walker et al. 1988; Erickson and O'Brien 1992; Desai and Mitchison 1997), in which microtubules coexist in states of growth and shrinkage and interconvert randomly between these two states. The observed in vivo dynamicity of microtubule ends, however, is quite different. Although the microtubule plus end is highly dynamic, the minus end is usually stable. The in vitro reconstitution of physiological microtubule dynamics was first achieved using purified centrosomes, tubulin, and the antagonistic proteins XKCM1 and XMAP215 (Kinoshita et al. 2001). Although these two proteins are among the best-understood MAPs to date, there is a plethora of proteins that regulate microtubule plus-end dynamics. In contrast, only a few proteins that specifically interact and regulate the microtubule minus end have been described so far.

\section{WHAT POWERS THE DYNAMIC BEHAVIOR AT THE MICROTUBULE PLUS END?}

The energy required for the dynamicity comes from GTP hydrolysis at the $\beta$-tubulin subunit after incorporation of the tubulin dimer into the microtubule lattice. When microtubules are grown with guanylyl- $(\alpha, \beta)$-methylenediphosphonate (GMPCPP), a nonhydrolyzable form of GTP, they do not undergo dynamic instability (Hyman et al. 1992), showing that GTP hydrolysis is necessary for the switching behavior. Although the relation of the four parameters of microtubule dynamic instability in pure tubulin solutions is well understood (Walker et al. 1988), it is particularly important to understand how individual proteins influence each of the four parameters (Bowne Anderson et al. 2013).

\section{MICROTUBULE DEPOLYMERASES}

$\mathrm{XKCM} 1$ is a member of the kinesin-13 family (Fig. 2). Unlike other kinesins, kinesin-13s do not move directionally along microtubules; instead, they employ their ATP-hydrolyzing motor domain to diffuse along the microtubule lattice to target both microtubule ends, and induce conformational changes that lead to microtubule depolymerization in vitro (Hunter et al. 2003; Helenius et al. 2006; Cooper et al. 2010; 


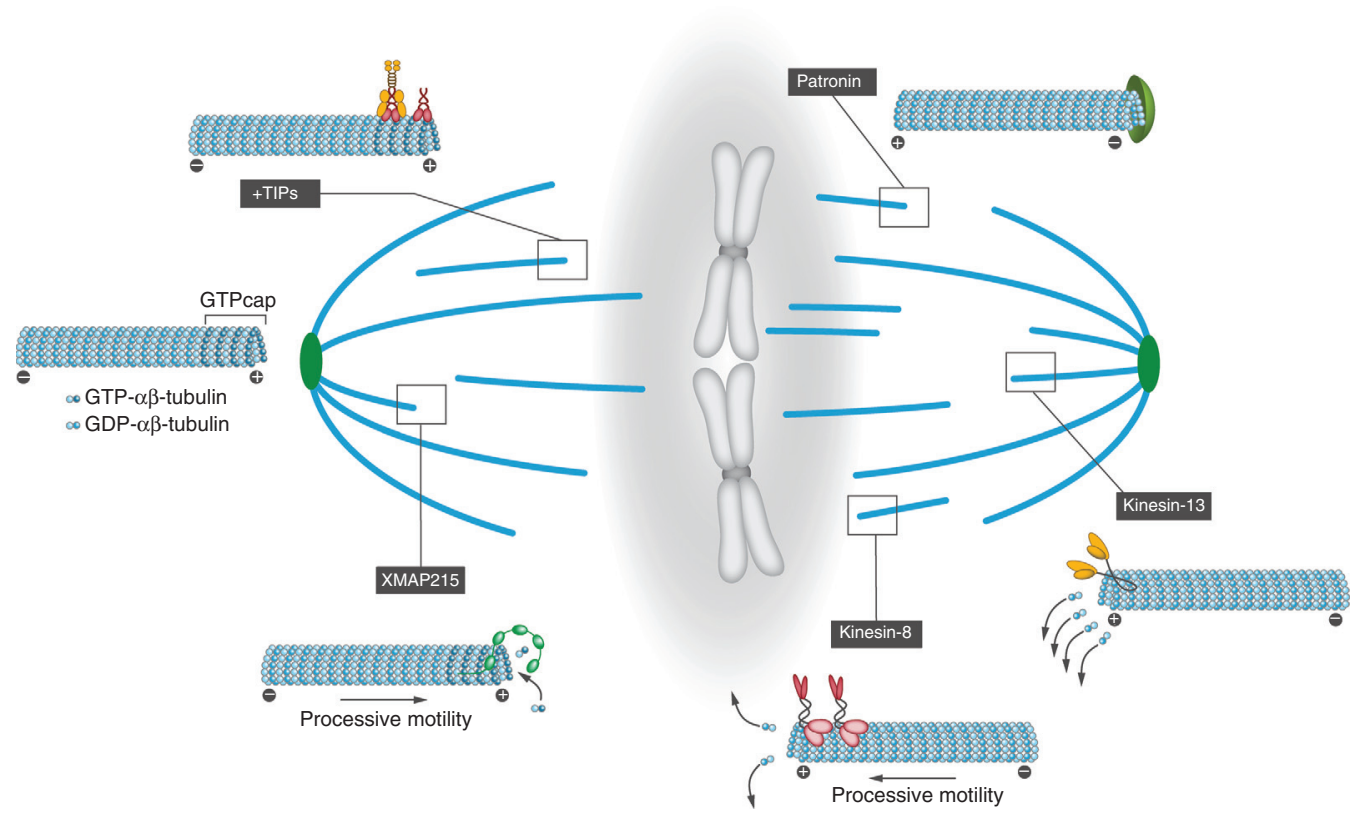

Figure 2. Microtubule dynamics. The intrinsic dynamic instability of microtubules is generated by guanosine triphosphate (GTP) hydrolysis at the nucleotide exchangeable site in $\beta$-tubulin. In addition, various proteins regulate the dynamic behavior of microtubules. Although microtubule - ends are specifically stabilized, for example, by patronin, the + ends switch stochastically between growing (regulated by polymerases such as XMAP215) and shrinking phases (regulated by depolymerases such as kinesin- 8 and -13). Growing microtubule + ends are further regulated by so-called microtubule plus-end tracking proteins (+TIPs). GDP, Guanosine diphosphate.

Oguchi et al. 2011). The unconventional ATPase cycle of kinesin-13 has optimized this motor protein for microtubule depolymerization (Friel and Howard 2011), explaining how structurally similar motor domains can have different functions. The kinesin-13 depolymerase activity accounts well for the cellular phenotypes caused by loss of its activity leading to a decrease in catastrophe rate and an increase in mitotic spindle length (Walczak et al. 1996; Desai et al. 1999; Tournebize et al. 2000; Rogers et al. 2004). Phenotypes upon loss of kinesin-13 function are very similar to those upon kinesin-8 loss. Inhibition of kinesin- 8 activity results in elongated spindles with hyperstable microtubules (Goshima et al. 2005; Mayr et al. 2007; Savoian and Glover 2010). Indeed, kinesin-8 proteins are slow plus-end directed motors with a high processivity that disassemble microtubules exclusively from one end (Fig. 2) (Varga et al. 2006). Surprisingly, kinesin-8 can depolymerize long microtubules faster than short ones. According to the "antenna model," longer microtubules accumulate more kinesin- 8 , which, because of its high processivity, will allow the motor to reach the microtubule plus end with a high probability. Therefore, kinesin-8 forms length-dependent "traffic jams" at the plus end, where an incoming kinesin- 8 will bump off a pausing kinesin- 8 molecule together with one or two tubulin dimers (Varga et al. 2009; Leduc et al. 2012). Such a cooperative mechanism leads to a length-dependent depolymerization rate and may serve as a model for how an ensemble of molecules can measure and control microtubule length.

Although experiments with purified proteins show that both kinesin- 8 and kinesin-13 can depolymerize stabilized microtubules (Desai et al. 1999; Hunter et al. 2003; Helenius et al. 2006; Varga et al. 2006, 2009; Mayr et al. 2007), a recent study found that they influence catastrophes by quite different mechanisms (Gardner et al. 2011). Catastrophes are thought to result from the loss of a stabilizing GTP-tubulin cap at 
the microtubule plus end. Although, for a long time, catastrophes were thought to be a singlestep process, Gardner and colleagues show that catastrophe frequency is intrinsically age dependent. The idea is that, during microtubule growth, "catastrophe-promoting events" accumulate over time and increase the likelihood of a catastrophe to happen. While kinesin- 8 increases the rate of catastrophe-promoting events, kinesin-13 reduces the number of events necessary for catastrophe (Gardner et al. 2011). Whether catastrophe-promoting events are structural defects in the microtubule lattice remains to be shown. The emerging picture thus is that kinesin-13s promote rapid and global restructuring of microtubules as, for example, required for spindle breakdown at the end of mitosis (Rankin and Wordeman 2010), while kinesin- 8 mediates fine tuning of microtubule length as, for example, required during chromosome congression and alignment (West et al. 2001; Mayr et al. 2007; Stumpff et al. 2008). In fungi, however, there is no kinesin-13, only one kinesin-8, Kip3, which does all of the jobs (Varga et al. 2006; Roostalu and Surrey 2013), while flies have three kinesin-13s: KLP10A, KLP59C, and KLP59D (Mennella et al. 2005; Schimizzi et al. 2010). Taken together, although both kinesin- 8 and kinesin-13 are catastrophe factors that dramatically affect microtubule lifetime, they will have a different effect on the microtubule length distribution in vivo. How microtubule length ultimately translates into spindle length remains to be shown.

\section{PLUS-END TRACKING PROTEINS}

Microtubule growth occurs by the addition of $\alpha \beta$-tubulin heterodimers with GTP bound in the exchangeable site of $\beta$-tubulin. Proteins of the XMAP215/Dis1 family catalyze this reaction (Fig. 2). In accordance with their prominent role as microtubule growth promoters, their depletion leads to shorter spindles or defects in spindle morphology in a variety of organisms (Matthews et al. 1998; Cullen et al. 1999; Tournebize et al. 2000; Garcia et al. 2001; Cassimeris and Morabito 2004). Members of the XMAP215/ Dis1 family are characterized by tumor overex- pressed gene (TOG) domains that function as $\alpha \beta$-tubulin-binding modules (Al-Bassam et al. 2007). The number of TOG domains is species dependent and varies from two to five (Gard and Kirschner 1987; Cassimeris and Morabito 2004; van Breugel et al. 2003). Structure function analyses revealed that TOG domains contribute differentially to the affinity of XMAP215 for the tubulin dimer and, thus, its polymerase activity (Widlund et al. 2011). Our current understanding of XMAP215 function is that it works as a processive polymerase (Brouhard et al. 2008). XMAP215 binds one free tubulin dimer via the TOG domains, interacts with the microtubule lattice via a specific microtubule-lattice-binding domain, and targets the microtubule plus ends by a diffusion-facilitated mechanism, where it persists for numerous rounds of tubulin subunit addition. XMAP215 is suggested to increase the association rate constant of GTP-tubulin by stabilizing a structural intermediate, which may correspond to a "collision complex" whose formation is very fast and diffusion limited (Brouhard et al. 2008).

XMAP215, together with EB1, synergistically reconstitutes physiological microtubule growth velocities $(>20 \mu \mathrm{m} / \mathrm{min})$ in vitro (Zanic et al. 2013). EB1 is a small dimeric, highly conserved plus-end tracking protein (+TIP), which specifically tracks growing, but not pausing or shrinking microtubules, by recognizing the tubulin nucleotide state within the microtubule (Fig. 2) (Zanic et al. 2009; Maurer et al. 2012). In contrast to XMAP215, EB1 does not track microtubule ends processively; instead, it exchanges with fast binding/unbinding kinetics (Bieling et al. 2007). How can we explain the synergistic effect of XMAP215 and EB1 on microtubule growth rates? The release of tubulin bound to XMAP215 was suggested to be dependent on the straightening of tubulin upon incorporation into the microtubule lattice (Ayaz et al. 2012). EB1 might accelerate the polymerase activity of XMAP215 by straightening protofilaments at the microtubule end through enhancement of lateral interactions between neighboring tubulin dimers (Zanic et al. 2013).

EB1 has been shown to mildly accelerate microtubule growth and catastrophe-stimulating 
effects in vitro (Bieling et al. 2007; Komarova et al. 2009; Zanic et al. 2013). Its main function, however, might be the regulation of a plus-end tracking proteins ( + TIPs) network. EB1 recruits other + TIPs via its carboxy-terminal EB homology domain. The majority of EB1-interacting + TIPs in turn binds EB1 via a short interaction motif residing in basic and serine-rich regions, named "SKIP" (or "SxIP") motif (Honnappa et al. 2009). Prominent examples are adenomatous polyposis coli (APC) (Honnappa et al. 2009), CLASPs (CLIP-associated proteins) (Honnappa et al. 2009; Kumar et al. 2012), SLAIN (van der Vaart et al. 2011), GTSE1 (Scolz et al. 2012), and microtubule depolymerases (Stout et al. 2011; Tanenbaum et al. 2011). In humans, the EB protein family includes three related members, EB1, EB2, and EB3, which are similar in structure and adopt homo- or heterodimeric conformations. The roles of EB2 and EB3 are less well understood. Recent studies, however, imply that differential regulation of EB proteins leads to specific functions throughout mitosis and cytokinesis (Ferreira et al. 2013).

CLASP proteins have emerged as a potential key player at the interface of microtubule and chromosome interactions, potentially by promoting microtubule rescue and suppressing microtubule catastrophe (Akhmanova et al. 2001; Cheeseman et al. 2005; Galjart 2005; Maiato et al. 2005; Mimori-Kiyosue et al. 2005; Drabek et al. 2006; Hannak and Heald 2006; Pereira et al. 2006; Sousa et al. 2007). Only recently, RanGTP, together with CLASP1, was implicated in mitotic spindle positioning (Bird et al. 2013). Although human CLASP1 was originally annotated as having only one TOG domain (Akhmanova et al. 2001), recent structural data report the crystal structure of a cryptic TOG domain (Leano et al. 2013). The identification of a second TOG domain in CLASP supports the idea that TOG domains function in arrays. How CLASPs mechanistically induce rescues is unknown. One possibility is that CLASP reverses microtubule disassembly by incorporating bound tubulin. Alternatively, CLASP could locally stabilize the depolymerizing microtubule lattice, possibly by preventing protofilament curling. Furthermore, it remains to be shown whether rescues play an essential role in spindle organization (Brugués et al. 2012). Direct visualization of rescue events within the metaphase spindle will help to solve these questions.

\section{WHAT KEEPS MICROTUBULE MINUS ENDS STABLE?}

Although microtubule minus ends are intrinsically dynamic in vitro (Desai and Mitchison 1997; Goodwin and Vale 2010), they are usually stable in vivo. So far, only very few minus-endspecific proteins have been described. Patronin, initially identified in the RNAi screen for Drosophila genes involved in spindle assembly as small spindle phenotype 4 (ssp4) (Goshima et al. 2007), is a capping protein that directly and selectively binds to the microtubule minus end in vitro and protects it from kinesin-13-dependent depolymerization (Fig. 2) (Goodwin and Vale 2010; Wang et al. 2013). It has been speculated that patronin specifically recognizes $\alpha$ tubulin and protects the minus end by sterically blocking kinesin-13 access. However, the mechanism by which patronin recognizes and protects the minus end remains elusive. In an alternative scenario, patronin could modify the morphology of the minus end by strengthening lateral protofilament interactions and thus reducing kinesin-13 affinity, which is known to prefer curved tubulin protofilaments (Asenjo et al. 2013). Three patronin homologs exist in humans (Baines et al. 2009). Their respective roles, however, are not yet defined, but they may have evolved to interact with distinct partners for localizing microtubule minus-end capping/anchoring activities to distinct subcellular regions (Berglund et al. 2008; Meng et al. 2008). Thus, the three patronin family members might provide new molecular tools for probing the organization and function of microtubules in different vertebrate cell types. Similarly, microspherule protein 1 (MCRS1), a protein that localizes to the microtubule minus-end region, has recently been shown to protect kinetochore fibers from depolymerization (Meunier and Vernos 2011).

Although the studies of microtubule plusend and minus-end binding proteins developed 
largely independent of each other, there is evidence of cross talk between the microtubule ends (Jiang and Akhmanova 2011). For example, it is known that XMAP215 is specifically recruited to the centrosome by the TACC family of proteins indicating that + TIPs function beyond microtubule plus-end regulation (Lee et al. 2001; Peset and Vernos 2008; Hubner et al. 2010). Therefore, studies of microtubule dynamics in the future should shift toward combining plus- and minus-end regulators and analyze their collective behavior.

\section{SPINDLE FORCES}

During assembly and function, the spindle passes through several steady states, each relying on a distinct balance of complementary and antagonistic forces. Loss-of-function studies in living cells suggested that a balance of forces generated by antagonistic motor proteins is crucial for spindle assembly and maintenance (Saunders et al. 1997; Mountain et al. 1999; Sharp et al. 1999a, 2000; Dumont and Mitchison 2009b). In addition, numerous theoretical works suggest that spindle size is dependent on the antagonism between motor proteins that slide microtubules in opposite directions (Burbank et al. 2007; Wollman et al. 2008; Ferenz et al. 2009; Loughlin et al. 2010; Brugués et al. 2012). The question of how these forces are integrated, as well as spatially and temporally regulated, to build a structure with a defined length and shape is too complex to be studied as a whole. One approach that helps to shed light on the increasing complexity of spindle forces is the in vitro reconstitution of minimal systems with a defined set of components. Minimal systems, such as antiparallel microtubule overlaps and astral microtubule arrays, have proven valuable systems to study organizational principles of spindle poles and the spindle midzone, respectively (Karsenti et al. 2006; Subramanian and Kapoor 2012; Dogterom and Surrey 2013).

\section{KINESIN-5 AND DYNEIN}

In cells lacking kinesin-5 activity, bipolar spindle assembly can be restored when cytoplasmic dynein is inhibited (Mitchison et al. 2005; Tanenbaum et al. 2008; Ferenz et al. 2009). These initial observations led to a model in which dynein-dependent inward forces directly counteract kinesin-5-dependent outward forces. In most organisms, apart from C. elegans (Saunders et al. 2007), kinesin-5 is absolutely essential for bipolar spindle assembly, and its loss results in the formation of monopolar spindles (Blangy et al. 1995; Mayer et al. 1999; Sharp et al. 1999b; Kapoor et al. 2000; Goshima and Vale 2003; Kwok et al. 2004). The homotetramer kinesin5 is a highly conserved plus-end-directed motor (Cole et al. 1994; Kashina et al. 1996), and its unique structure is optimized to cross-link and slide antiparallel microtubules (Fig. 3) (Hentrich and Surrey 2010), thereby producing the necessary outward force that drives centrosome separation during spindle assembly (Splinter et al. 2010; Tanenbaum and Medema 2010). Cytoplasmic dynein, on the other hand, is the major motor responsible for microtubule minus-end-directed movements in most eukaryotic cells. Compared to kinesins, cytoplasmic dynein is unique as it belongs to the $\mathrm{AAA}^{+}$family. Dynein is a dimer of two heavy chains, each composed of an AAA ring that binds and hydrolyzes ATP, a microtubule-binding stalk, and a long tail domain (Fig. 3) (Carter et al. 2011). In mitosis, dynein is involved in centrosome separation, chromosome movements, spindle organization in particular pole focusing, kinetochore activity, checkpoint silencing, and spindle positioning (Vaisberg et al. 1993; Gaglio et al. 1996; Heald et al. 1996; Merdes et al. 1996; Busson et al. 1998; Gönczy et al. 1999, 2000; Sharp et al. 1999a; Howell et al. 2001; Grill and Hyman 2005; Varma et al. 2008; Sivaram et al. 2009; Bader and Baughan 2010; Kiyomitsu and Cheeseman 2012; Laan et al. 2012).

This simplified view, in which dyneindependent inward forces directly counteract kinesin-5-dependent outward forces, has recently been challenged by the observation that kinesin5 activity is not titratable against dynein activity, suggesting that dynein most likely antagonizes kinesin-5 indirectly by exerting force at different spindle locations (Florian and Mayer 2012). Indeed, both kinesin-5 and cytoplasmic 


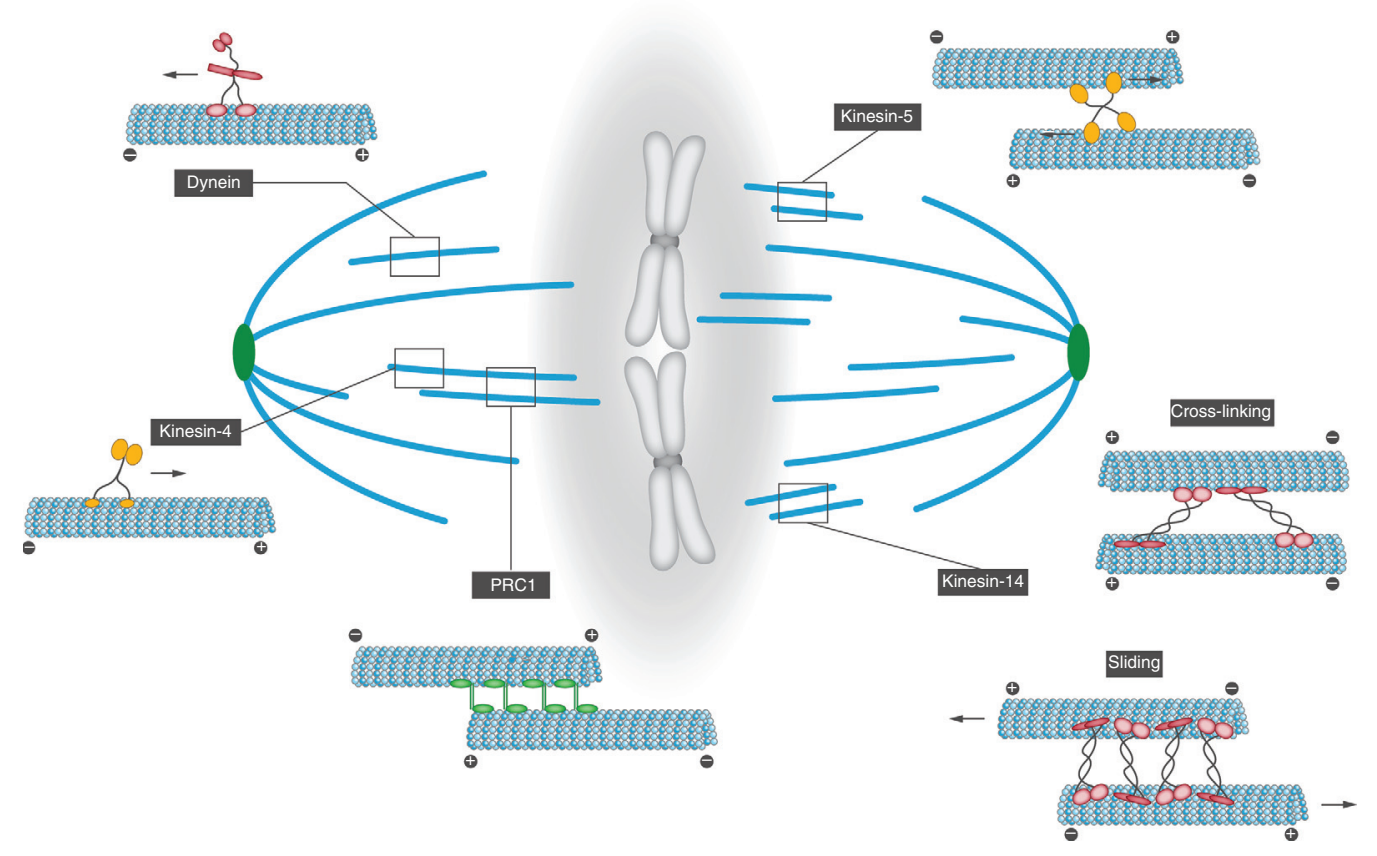

Figure 3. Spindle forces. During assembly and function, the spindle passes through several steady states, each relying on a distinct balance of complementary and antagonistic forces. The homotetramer kinesin-5 is a highly conserved plus-end-directed motor optimized to cross-link and slide antiparallel microtubules, thereby producing outward forces that drive centrosome separation during spindle assembly. Kinesin-4 is a dimeric plusend-directed motor. Together with PRC1, it forms antiparallel microtubule overlaps with precisely defined lengths; while PRC1 marks the microtubule overlap region and recruits kinesin-4, the motor protein walks processively to microtubule ends in the overlap region, where its accumulation leads to the inhibition of microtubule growth. In contrast to the plus-end-directed motility of other kinesin proteins, kinesin-14 is a minus-end-directed motor that can either slide antiparallel microtubules or cross-link parallel microtubules (adapted from Fink et al. 2009). Cytoplasmic dynein is the major motor responsible for microtubule minusend-directed movements.

dynein localize to multiple subcellular structures throughout mitosis. At the spindle center, kinesin-5 is proposed to drive microtubule flux by antiparallel microtubule sliding, while the dynein-dependent concentration of kinesin-5 at spindle poles is suggested to contribute to parallel microtubule cross-linking (Uteng et al. 2008). Cytoplasmic dynein localizes to centrosomes, kinetochores, spindle microtubules, and the cell cortex (Pfarr et al. 1990; Steuer et al. 1990; Dujardin and Vallee 2002; Tanenbaum and Medema 2010; Kiyomitsu and Cheeseman 2012). Taking these diverse localizations and functions into consideration, it is not surprising that the depletion of multifunctional proteins results in complex patterns of spindle forma- tion. In the case of dynein, the situation is even more complicated by the fact that several accessory proteins modulate dynein to carry out its many different functions. Prominent examples are the dynactin complexes, LIS1 and NudE (Kardon and Vale 2009; Huang et al. 2012). In the future, it will be interesting to learn how these accessory proteins regulate the detailed function of dynein. Recent exciting advances in the in vitro reconstitution of human dynein (Trokter et al. 2012) and the observation of single dynein molecules in cells (Ananthanarayanan et al. 2013; Rai et al. 2013) will help to advance our understanding of the structural basis of dynein movement and determine how the motor regulation works. 


\section{KINESIN-5 AND KINESIN-14}

In other systems, kinesin-5 activity is proposed to be antagonized by the inward sliding activity of kinesin-14. Kinesin-14 is a minus-enddirected homodimeric motor (Fig. 3), which uses a pair of motor domains to walk on one microtubule and a nonmotor domain to interact with the second filament. To cross-link two microtubules, kinesin-14 orients stochastically and its motor domains are equally likely to bind either of the two filaments (Braun et al. 2009; Fink et al. 2009). In vitro, kinesin-14 can autonomously induce pole-formation (Hentrich and Surrey 2010), which might be the dominant mechanism by which centrosome-free meiotic spindles are focused in Drosophila (Matthies et al. 1996; Sköld et al. 2005). Reconstitution studies combining these two antagonistic motors, however, fail to establish a stable antiparallel microtubule overlap (Tao et al. 2006; Hentrich and Surrey 2010) but generate oscillatory movements, as previously observed in microtubule gliding assays with kinesin-1 and dynein (Vale et al. 1992). Thus, a persistent force balance cannot be achieved by either of these two motor combinations.

\section{KINESIN-14 AND ASE1}

Instead, a three-component system consisting of microtubules, kinesin-14, and Ase1, a nonmotor cross-linking protein, was shown to form stable antiparallel microtubule overlaps (Braun et al. 2011). Members of the conserved Ase1/ PRC1 family are characterized by their ability to bind to antiparallel microtubule overlaps with high affinity and selectively cross-link them in vitro (Fig. 3) (Janson et al. 2007; Kapitein et al. 2008; Bieling et al. 2010; Subramanian et al. 2010, 2013; Duellberg et al. 2013). In yeast, the spindle midzone is marked by Ase1 localization and defined by the Ase-1-dependent recruitment of all other midzone proteins (Khmelinskii et al. 2007). PRC1, the Ase1 homolog in higher eukaryotes, also selectively binds antiparallel microtubule overlaps (Bieling et al. 2010; Subramanian et al. 2010). Whether PRC1, together with kinesin-14, can set an antiparallel microtubule array with a defined overlap length has not yet been tested. However, it was shown to not substantially oppose kinesin-5 activity (Subramanian et al. 2010).

\section{PRC1 AND KINESIN-4}

The question of how antiparallel microtubules are established in metazoan metaphase spindles is still open as PRC1 is not crucial for spindle organization before anaphase (Mollinari et al. 2002). Only after anaphase onset, PRC1 is essential to maintain the overlap length of the central spindle (Kurasawa et al. 2004; Hu et al. 2011), where it recruits kinesin-4. Kinesin-4, a dimeric plus-end-directed motor (Fig. 3), has an inhibitory effect on microtubule growth (Bringmann et al. 2004). Two recent studies show that PRC1, together with kinesin-4, is sufficient to form antiparallel microtubule overlaps with precisely defined lengths in vitro (Bieling et al. 2010; Subramanian et al. 2013). PRC1 and kinesin-4 tag microtubule plus ends. While PRC1 marks the microtubule overlap region and recruits kine$\sin -4$, the motor protein walks processively to microtubule ends in the overlap region, where its accumulation leads to the inhibition of microtubule growth. Importantly, plus-end tagging by PRC1 is microtubule length dependent, and, thus, nicely demonstrates a biochemical mechanism by which the length of antiparallel overlaps can be controlled by suppression of microtubule dynamics.

\section{MODELING SPINDLE ASSEMBLY USING Xenopus EXTRACTS}

Dynamic spindles assembled in Xenopus egg extracts are a powerful way to unravel principles of self-organization. The egg extract is an open system that permits biochemical manipulation and quantitative kinetic studies. In addition, this cell-free system is void of cortical restrictions and spindle material is not limited, which allows studying intrinsic mechanisms of spindle organization. In combination with theoretical and conceptual approaches, it is a particular powerful tool to describe complex dynamic processes. Thus, in recent years, this easily trac- 
table system has led to an outpouring of nonmutually-exclusive models that quantitatively describe spindle organization, which we will shortly discuss.

A two-dimensional simulation study by Loughlin and colleagues implemented many processes relevant for Xenopus spindle assembly, such as microtubule nucleation and dynamics, steric interactions between microtubules, and motor-induced sliding (Loughlin et al. 2010). This model predicts that microtubule nucleation occurs throughout the spindle and that spindle morphology and, in particular, spindle lengths, are governed by selective microtubule destabilization near the spindle poles. In contrast, in a different model called the "slide-andcluster" mechanism (Burbank et al. 2007), microtubules nucleate only locally near chromosomes, slide outward by a plus-end-directed motor, cluster by a minus-end-directed motor, and are lost by turnover throughout the spindle. An important feature of the slide-and-cluster model is that the model does not require specific depolymerization of microtubule minus ends at predefined poles. Thus, spindle length primarily emerges as the product of outward sliding velocity and minus-end lifetimes. This, however, requires microtubule lifetimes that are significantly higher than those measured in metaphase spindles (Needlemann et al. 2010).

The above models make distinct predictions for the length distribution and organization of spindle microtubules. Only recently, Brugués and colleagues developed a method to quantitatively measure the length distribution and polarity of microtubules within the spindle. They found that microtubules are shortest at the poles and progressively increase in length toward the center of the spindle. In the spindle center, an equal number of microtubules points in both directions, whereas close to the pole, the majority of microtubules are oriented with their plus end away from the pole (Brugués et al. 2012). Combining these experiments with modeling, the authors suggest that microtubule organization in the spindle is determined by nonuniform microtubule nucleation and local sorting of microtubules by transport. They, however, did not find evidence for spatially varying microtubule stability. The nonuniform nucleation close to chromatin could be consistent with a gradient of microtubule nucleation around chromatin or microtubule-dependent nucleation.

Although all of the above studies predict that microtubule nucleation has a profound influence on spindle organization and length, so far, no one has been able to directly measure microtubule nucleation rates within spindles. It therefore remains unknown how different nucleation mechanisms (i.e., chromatin-mediated and microtubule-dependent microtubule nucleation) contribute to the overall spindle architecture. Thus, measurement of nucleation rates in spindles will be an important topic for the future.

\section{SPINDLE SIZE CONTROL AND SCALING}

The metaphase spindle needs to function in cell volumes that vary by several orders of magnitude. Thus, the spindle has to be long enough to span sufficient distance to physically separate chromosomes. Because defects in spindle length result in erroneous cell division (Dumont et al. 2007), robust mechanisms to set the length of a spindle and scale it according to cell size must exist. In its simplest form, spindle length could be constrained by physical cellular boundaries just as the size of asters in frog and fish oocytes (Wühr et al. 2010). Robust size control could also be achieved through so-called dynamic balance models (Chan and Marshall 2012). These models rely on either assembly or disassembly being size dependent such that they balance at one parameter-specified size or balance point. Such a mechanism fits well with a recent mass balance model of spindle length, with the steadystate spindle size effectively set by the balance of microtubule assembly and disassembly (Reber et al. 2013). Alternatively, cell size could control the length of the spindle by providing a finite cytoplasmic volume, where a key component present in limiting amounts is depleted as the structure assembles (Good et al. 2013; Hazel et al. 2013). A number of factors have been suggested to contribute to setting spindle length (see below), and it will be interesting to determine the relevant ones that govern scaling in 
different contexts (Goshima et al. 2005; Dumont and Mitchison 2009a,b; Loughlin et al. 2011; Reber et al. 2013; Wilbur and Heald 2013a).

The challenge of scale is particularly apparent during early development, when cell growth and division are uncoupled. During Xenopus embryogenesis, for example, cell size dramatically decreases. The $1200-\mu \mathrm{m}$-diameter fertilized egg divides and gives rise to approximately $12-\mu \mathrm{m}$-diameter blastomeres (Montorzi et al. 2000). During the first mitoses, spindle length is uncoupled from cell size and reaches an upper limit of approximately $60 \mu \mathrm{m}$ through mechanisms proposed to be intrinsic to the spindle (Wühr et al. 2008). Later in Xenopus egg development, a strong correlation between spindle length and cell size emerges. This has been shown in Xenopus embryos and extracts from fertilized embryos that recapitulate in vivo spindle size differences (Wühr et al. 2008; Wilbur and Heald 2013b). Two recent studies, which encapsulate extracts from Xenopus eggs or embryos in droplets of varying size, confirm that metaphase spindle length and width scale with droplet size in vitro (Good et al. 2013; Hazel et al. 2013), suggesting that cytoplasmic volume could limit the amount of material for assembly. Interestingly, in embryonic extracts from haploid embryos, spindle size is only reduced by approximately $10 \%$. This difference is similar to the DNA-dependent length difference observed previously (Brown et al. 2007; Dinarina et al. 2009) indicating that signaling from chromatin contributes to setting spindle length but is not a major factor. Instead, microtubule stability appears to be a robust mechanism for determining spindle length in Xenopus egg extracts, and factors controlling microtubule dynamics are likely to scale spindle length. Indeed, kinesin-13 was shown to be inhibited during early developmental stages by the transport receptor importin $\alpha$, and activated in later stages when importin $\alpha$ partitions to a membrane pool (Wilbur and Heald 2013b). This mechanism is directly linked to changes in the surface membrane to cell volume ratio and thus suitable for developmental scaling.

Interestingly, the smaller relative of $X$. laevis, $X$. tropicalis, has correspondingly smaller cells, nuclei, and spindles (Levy and Heald 2012). Recent work has shown that the observed differences in spindle size are recapitulated in respective egg extracts. $X$. tropicalis spindles are approximately $30 \%$ shorter than $X$. laevis spindles. What is the underlying cause of spindle size difference in the two extracts? Mixed extracts produce spindles of intermediate sizes revealing a dynamic, dose-dependent regulation of spindle size by cytoplasmic factors (Brown et al. 2007). Based on a computational model of meiotic spindle assembly, which predicted that higher localized microtubule depolymerization rates could generate shorter spindles (Loughlin et al. 2010), a single phosphorylation site in katanin was identified as the source of the spindle size differences in the two related frog species. Phosphorylation by the mitotic kinase Aurora B lowers the katanin activity in $X$. laevis, while $X$. tropicalis katanin lacking this phosphorylation site remains active. Consequently, a decrease in microtubule stability causes the shorter spindles in X. tropicalis egg extract (Loughlin et al. 2011). This study nicely shows that, in different species, mechanisms have evolved to modulate the intrinsic size of the metaphase spindle. However, it remains to be understood why the $X$. tropicalis spindle needs to be shorter in the first place. Perhaps this is because of later constraints in development that arise as cells become increasingly small, which, in tropicalis, may occur sooner given its smaller initial size.

Correlations of spindle length and width with cell size have also been shown in C. elegans embryos (Hara and Kimura 2009, 2013; Greenan et al. 2010) and Mus musculus (Fitzharris 2009; Courtois et al. 2012). Greenan and colleagues (2010) showed that spindle length correlates with centrosome size through development and that a reduction of centrosome size reduces spindle length. Mechanistically, the authors suggest that centrosome size sets mitotic spindle length by controlling the length scale of a TPX2 gradient along spindle microtubules (Greenan et al. 2010). This is consistent with previous results in human cells, which show that introducing point mutations in TPX2, which abolish the interaction between TPX2 and Aurora A, results in small spindles (Bird 
and Hymann 2008). If centrosome size sets spindle size, what then controls the size of the centrosome? Decker and colleagues propose that limiting amounts of centrosome material set the size of the centrosome in C. elegans embryos (Decker et al. 2011). The idea is that when centrosomes grow in a finite volume, the cytoplasmic concentration of a limiting (structural) factor will gradually decrease as centrosomes bind and sequester material from the cytoplasm. Such a limiting component system may be a general way of limiting the size of intracellular organelles in systems with fast cell cycles and rapidly changing cell volume (Coyne and Rosenbaum 1970; Stephens 1989; Norrander et al. 1995; Bullitt et al. 1997; Elliott et al. 1999; Brangwynne et al. 2009, 2011; Goehring et al. 2011; Goehring and Hyman 2012; Feric and Brangwynne 2013). The great advantage of the limiting component system is to provide a robust and rapid system that takes advantage of the contribution of a defined amount of maternal cytoplasm to the embryo. Whether similar mechanisms also apply in somatic systems, with longer cell cycles and smaller changes in cell size, is an important direction for future investigation.

\section{OUTLOOK}

Here, we have discussed how throughout the last decade, three different directions have converged to suggest that reconstitution of a mitotic spindle might soon be possible. These are the cataloging of spindle components, their in vitro expression and biochemical and physical characterization in minimal systems, and increasingly developed theory. An in vitro reconstitution of the metaphase spindle from purified components will likely begin as a spindle similar to a Xenopus oocyte spindle, in which the dynamics of microtubules are dominated by chromatin. However, the increasingly sophisticated reconstitution of kinetochores and centrosomes suggest that a full reconstitution of a functional spindle will be possible. This will indeed be a triumphant conclusion to the work of Walther Flemming almost 150 years ago, who could hardly have conceived of such an achievement.

\section{ACKNOWLEDGMENTS}

The authors thank Drs. Alexander Bird, Josh Currie, David Drechsler, and Hugo Bowne-Anderson for comments and suggestions on the manuscript and Franziska Friedrich for help with the figures. Furthermore, we thank all present and past members of the Hyman and Jülicher Laboratories for valuable discussions. S.R. is supported by the European Commission's 7th Framework Programme Grant Systems Biology of Stem Cells and Reprogramming (HEALTH-F7-2010-242129/SyBoSS) and a fellowship by the Wissenschaftskolleg zu Berlin.

\section{REFERENCES}

Akhmanova A, Hoogenraad CC, Drabek K, Stepanova T, Dortland B, Verkerk T, Vermeulen W, Burgering BM, De Zeeuw CI, Grosveld F, et al. 2001. Clasps are CLIP115 and -170 associating proteins involved in the regional regulation of microtubule dynamics in motile fibroblasts. Cell 104: 923-935.

Al-Bassam J, Larsen NA, Hyman AA, Harrison SC. 2007. Crystal structure of a TOG domain: Conserved features of XMAP215/Dis1-family TOG domains and implications for tubulin binding. Structure 15: 355-362.

Ananthanarayanan V, Schattat M, Vogel SK, Krull A, Pavin N, Tolić-Nørrelykke IM. 2013. Dynein motion switches from diffusive to directed upon cortical anchoring. Cell 153: $1526-1536$.

Asenjo AB, Chatterjee C, Tan D, DePaoli V, Rice WJ, DiazAvalos R, Silvestry M, Sosa H. 2013. Structural model for tubulin recognition and deformation by kinesin-13 microtubule depolymerases. Cell Rep 3: 759-768.

Ayaz P, Ye X, Huddleston P, Brautigam CA, Rice LM. 2012. A TOG: $\alpha \beta$-tubulin complex structure reveals conformation-based mechanisms for a microtubule polymerase. Science 337: 857-860.

Bader JR, Baughan KT. 2010. Dynein at the kinetochore: Timing, interactions and functions. Semin Cell Dev Biol 21: 269-275.

Baines AJ, Bignone PA, King MD, Maggs AM, Bennett PM, Pinder JC, Phillips GW. 2009. The CKK domain (DUF1781) binds microtubules and defines the CAMSAP/ssp4 family of animal proteins. Mol Biol Evol 26: 2005-2014.

Basto R, Lau J, Vinogradova T, Gardiol A, Woods CG, Khodjakov A, Raff JW. 2006. Flies without centrioles. Cell 125: 1375-1386.

Berdahl A, Torney CJ, Ioannou CC, Faria JJ, Couzin ID. 2013. Emergent sensing of complex environments by mobile animal groups. Science 339: 574-576.

Berglund L, Björling E, Oksvold P, Fagerberg L, Asplund A, Szigyarto CA, Persson A, Ottosson J, Wernérus H, Nilsson P, et al. 2008. A genecentric Human Protein Atlas for expression profiles based on antibodies. Mol Cell Proteomics 7: 2019-2027. 
Bieling P, Laan L, Schek H, Munteanu EL, Sandblad L, Dogterom M, Brunner D, Surrey T. 2007. Reconstitution of a microtubule plus-end tracking system in vitro. Nature 450: 1100-1105.

Bieling P, Telley IA, Surrey T. 2010. A minimal midzone protein module controls formation and length of antiparallel microtubule overlaps. Cell 142: 420-432.

Bird AW, Hymann AA. 2008. Building a spindle of the correct length in human cells requires the interaction between TPX2 and Aurora A. J Cell Biol 182: 289-300.

Bird SL, Heald R, Weis K. 2013. RanGTP and CLASP1 cooperate to position the mitotic spindle. Mol Biol Cell 24: 2506-2514.

Blangy A, Lane HA, d'Hérin P, Harper M, Kress M, Nigg EA. 1995. Phosphorylation by p34cdc2 regulates spindle association of human Eg5, a kinesin-related motor essential for bipolar spindle formation in vivo. Cell 83: 11591169.

Bowne-Anderson H, Zanic M, Kauer M, Howard J. 2013. Microtubule dynamic instability: A new model with coupled GTP hydrolysis and multistep catastrophe. Bioessays 35: 452-461.

Brangwynne CP, Eckmann CR, Courson DS, Rybarska A, Hoege C, Gharakhani J, Jülicher F, Hyman AA. 2009. Germline P granules are liquid droplets that localize by controlled dissolution/condensation. Science 324: 1729-1732.

Brangwynne CP, Mitchison TJ, Hyman AA. 2011. Active liquid-like behavior of nucleoli determines their size and shape in Xenopus laevis oocytes. Proc Natl Acad Sci 108: $4334-4339$.

Braun M, Drummond DR, Cross RA, McAinsh AD. 2009. The kinesin-14 Klp2 organizes microtubules into parallel bundles by an ATP-dependent sorting mechanism. Nat Cell Biol 11: 724-730.

Braun M, Lansky Z, Fink G, Ruhnow F, Diez S, Janson ME. 2011. Adaptive braking by Asel prevents overlapping microtubules from sliding completely apart. Nat Cell Biol 13: $1259-1264$.

Bringmann H, Skiniotis G, Spilker A, Kandels-Lewis S, Vernos I, Surrey T. 2004. A kinesin-like motor inhibits microtubule dynamic instability. Science 303: 1519-1522.

Brouhard GJ, Stear JH, Noetzel TL, Al-Bassam J, Kinoshita K, Harrison SC, Howard J, Hyman AA. 2008. XMAP215 is a processive microtubule polymerase. Cell 132: 79-88.

Brown KS, Blower MD, Maresca TJ, Grammer TC, Harland RM, Heald R. 2007. Xenopus tropicalis egg extracts provide insight into scaling of the mitotic spindle. J Cell Biol 176: $765-770$.

Brugués J, Nuzzo V, Mazur E, Needleman DJ. 2012. Nucleation and transport organize microtubules in metaphase spindles. Cell 149: 554-564.

Brunet S, Sardon T, Zimmerman T, Wittmann T, Pepperkok R, Karsenti E, Vernos I. 2004. Characterization of the TPX2 domains involved in microtubule nucleation and spindle assembly in Xenopus egg extracts. Mol Biol Cell 15: $5318-5328$.

Bullitt E, Rout MP, Kilmartin JV, Akey CW. 1997. The yeast spindle pole body is assembled around a central crystal of Spc42p. Cell 89: 1077-1086.
Emergent Properties of the Metaphase Spindle

Burbank KS, Groen AC, Perlman ZE, Fisher DS, Mitchison TJ. 2006. A new method reveals microtubule minus ends throughout the meiotic spindle. J Cell Biol 175: 369-375.

Burbank KS, Mitchison TJ, Fisher DS. 2007. Slide-and-cluster models for spindle assembly. Curr Biol 17: 13731383.

Busson S, Dujardin D, Moreau A, Dompierre J, De Mey JR. 1998. Dynein and dynactin are localized to astral microtubules and at cortical sites in mitotic epithelial cells. Curr Biol 8: 541-544.

Buster D, McNally K, McNally FJ. 2002. Katanin inhibition prevents the redistribution of $\gamma$-tubulin at mitosis. J Cell Sci 115: 1083-1092.

Carazo-Salas RE, Guarguaglini G, Gruss OJ, Segref A, Karsenti E, Mattaj IW. 1999. Generation of GTP-bound Ran by RCC1 is required for chromatin-induced mitotic spindle formation. Nature 400: 178-181.

Carazo-Salas RE, Gruss OJ, Mattaj IW, Karsenti E. 2001. Ran-GTP coordinates regulation of microtubule nucleation and dynamics during mitotic-spindle assembly. Nat Cell Biol 3: 228-234.

Carter AP, Cho C, Jin L, Vale RD. 2011. Crystal structure of the dynein motor domain. Science 331: 1159-1165.

Cassimeris L. 2002. The oncoprotein 18/stathmin family of microtubule destabilizers. Curr Opin Cell Biol 14: 18-24.

Cassimeris L, Morabito J. 2004. TOGp, the human homolog of XMAP215/Dis1, is required for centrosome integrity, spindle pole organization, and bipolar spindle assembly. Mol Biol Cell 15: 1580-1590.

Chan YH, Marshall WF. 2012. How cells know the size of their organelles. Science 337: 1186-1189.

Cheeseman IM, MacLeod I, Yates JR 3rd, Oegema K, Desai A. 2005. The CENP-F-like proteins HCP-1 and HCP-2 target CLASP to kinetochores to mediate chromosome segregation. Curr Biol 15: 771-777.

Clarke PR, Zhang C. 2008. Spatial and temporal coordination of mitosis by Ran GTPase. Nat Rev Mol Cell Biol 9: 464-477.

Clausen T, Ribbeck K. 2007. Self-organization of anastral spindles by synergy of dynamic instability, autocatalytic microtubule production, and a spatial signaling gradient. PLOS ONE 2: e244.

Cole DG, Saxton WM, Sheehan KB, Scholey JM. 1994. A "slow" homotetrameric kinesin-related motor protein purified from Drosophila embryos. J Biol Chem 269: 22913-22916.

Colombié N, Głuszek AA, Meireles AM, Ohkura H. 2013. Meiosis-specific stable binding of augmin to acentrosomal spindle poles promotes biased microtubule assembly in oocytes. PLoS Genet 9: e1003562.

Cooper JR, Wagenbach M, Asbury CL, Wordeman L. 2010. Catalysis of the microtubule on-rate is the major parameter regulating the depolymerase activity of MCAK. Nat Struct Mol Biol 17: 77-82.

Courtois A, Schuh M, Ellenberg J, Hiiragi T. 2012. The transition from meiotic to mitotic spindle assembly is gradual during early mammalian development. J Cell Biol 198: 357-370.

Coyne B, Rosenbaum JL. 1970. Flagellar elongation and shortening in chlamydomonas: II. Re-utilization of flagellar proteins. J Cell Biol 47: 777-781. 
Cullen CF, Deák P, Glover DM, Ohkura H. 1999. mini spindles: A gene encoding a conserved microtubule-associated protein required for the integrity of the mitotic spindle in Drosophila. J Cell Biol 146: 1005-1018.

Decker M, Jaensch S, Pozniakovsky A, Zinke A, O'Connell KF, Zachariae W, Myers E, Hyman AA. 2011. Limiting amounts of centrosome material set centrosome size in C. elegans embryos. Curr Biol 21: 1259-1267.

De Mey J, Lambert AM, Bajer AS, Moeremans M, De Brabander M. 1982. Visualization of microtubules in interphase and mitotic plant cells of Haemanthus endosperm with the immuno-gold staining method. Proc Natl Acad Sci 79: 1898-1902.

Desai A, Mitchison TJ. 1997. Microtubule polymerization dynamics. Annu Rev Cell Dev Biol 13: 83-117.

Desai A, Verma S, Mitchison TJ, Walczak CE. 1999. Kin I kinesins are microtubule-destabilizing enzymes. Cell 96: 69-78.

Díaz-Valencia JD, Morelli MM, Bailey M, Zhang D, Sharp DJ, Ross JL. 2011. Drosophila katanin-60 depolymerizes and severs at microtubule defects. Biophys J 100: 24402449.

Dinarina A, Pugieux C, Corral MM, Loose M, Spatz J, Karsenti E, Nédélec F. 2009. Chromatin shapes the mitotic spindle. Cell 138: 502-513.

Dogterom M, Yurke B. 1997. Measurement of the forcevelocity relation for growing microtubules. Science 278: 856-860.

Dogterom M, Surrey T. 2013. Microtubule organization in vitro. Curr Opin Cell Biol 25: 23-29.

Drabek K, van Ham M, Stepanova T, Draegestein K, van Horssen R, Sayas CL, Akhmanova A, Ten Hagen T, Smits R, Fodde R, et al. 2006. Role of CLASP2 in microtubule stabilization and the regulation of persistent motility. Curr Biol 16: 2259-2264.

Duellberg C, Fourniol FJ, Maurer SP, Roostalu J, Surrey T. 2013. End-binding proteins and Ase1/PRC1 define local functionality of structurally distinct parts of the microtubule cytoskeleton. Trends Cell Biol 23: 54-63.

Dujardin DL, Vallee RB. 2002. Dynein at the cortex. Curr Opin Cell Biol 14: 44-49.

Dumont J, Desai A. 2012. Acentrosomal spindle assembly and chromosome segregation during oocyte meiosis. Trends Cell Biol 22: 241-249.

Dumont S, Mitchison TJ. 2009a. Compression regulates mitotic spindle length by a mechanochemical switch at the poles. Curr Biol 19: 1086-1095.

Dumont S, Mitchison TJ. 2009b. Force and length in the mitotic spindle. Curr Biol 19: R749-R761.

Dumont J, Petri S, Pellegrin F, Terret ME, Bohnsack MT, Rassinier P, Georget V, Kaláb P, Gruss OJ, Verlhac MH. 2007. A centriole- and RanGTP-independent spindle assembly pathway in meiosis I of vertebrate oocytes. J Cell Biol 176: 295-305.

Elliott S, Knop M, Schlenstedt G, Schiebel E. 1999. Spc29p is a component of the Spc110p subcomplex and is essential for spindle pole body duplication. Proc Natl Acad Sci 96: 6205-6210.

Erickson HP, O’Brien ET. 1992. Microtubule dynamic instability and GTP hydrolysis. Annu Rev Biophys Biomol Struct 21: 145-166.
Eyers PA, Maller JL. 2004. Regulation of Xenopus Aurora A activation by TPX2. J Biol Chem 279: 9008-9015.

Ferenz NP, Paul R, Fagerstrom C, Mogilner A, Wadsworth P. 2009. Dynein antagonizes eg 5 by crosslinking and sliding antiparallel microtubules. Curr Biol 19: 1833-1838.

Feric M, Brangwynne CP. 2013. A nuclear F-actin scaffold stabilizes ribonucleoprotein droplets against gravity in large cells. Nat Cell Biol 15: 1253-1259.

Ferreira JG, Pereira AJ, Akhmanova A, Maiato H. 2013. Aurora B spatially regulates EB3 phosphorylation to coordinate daughter cell adhesion with cytokinesis. J Cell Biol 201: 709-724.

Fink G, Hajdo L, Skowronek KJ, Reuther C, Kasprzak AA, Diez S. 2009. The mitotic kinesin-14 Ncd drives directional microtubule-Microtubule sliding. Nat Cell Biol 11: $717-723$.

Fitzharris G. 2009. A shift from kinesin 5-dependent metaphase spindle function during preimplantation development in mouse. Development 136: 2111-2119.

Flemming W. 1882. Zellsubstanz, Kern und Zelltheilung. F.C.W. Vogel, Leipzig.

Florian S, Mayer TU. 2012. The functional antagonism between Eg5 and dynein in spindle bipolarization is not compatible with a simple push-pull model. Cell Rep 1: $408-416$.

Friel CT, Howard J. 2011. The kinesin-13 MCAK has an unconventional ATPase cycle adapted for microtubule depolymerization. EMBO J 30: 3928-3939.

Gaglio T, Saredi A, Bingham JB, Hasbani MJ, Gill SR, Schroer TA, Compton DA. 1996. Opposing motor activities are required for the organization of the mammalian mitotic spindle pole. J Cell Biol 135: 399-414.

Galjart N. 2005. CLIPs and CLASPs and cellular dynamics. Nat Rev Mol Cell Biol 6: 487-498.

Garcia MA, Vardy L, Koonrugsa N, Toda T. 2001. Fission yeast ch-TOG/XMAP215 homologue Alp14 connects mitotic spindles with the kinetochore and is a component of the Mad2-dependent spindle checkpoint. EMBO J 20: 3389-3401.

Gard DL, Kirschner MW. 1987. A microtubule-associated protein from Xenopus eggs that specifically promotes assembly at the plus-end. J Cell Biol 105: 2203-2215.

Gardner MK, Zanic M, Gell C, Bormuth V, Howard J. 2011. Depolymerizing kinesins Kip3 and MCAK shape cellular microtubule architecture by differential control of catastrophe. Cell 147: 1092-1103.

Gennerich A, Vale RD. 2009. Walking the walk: How kinesin and dynein coordinate their steps. Curr Opin Cell Biol 21: 59-67.

Goehring NW, Hyman AA. 2012. Organelle growth control through limiting pools of cytoplasmic components. Curr Biol 22: R330-R339.

Goehring NW, Trong PK, Bois JS, Chowdhury D, Nicola EM, Hyman AA, Grill SW. 2011. Polarization of PAR proteins by advective triggering of a pattern-forming system. Science 334: 1137-1141.

Gönczy P, Pichler S, Kirkham M, Hyman AA. 1999. Cytoplasmic dynein is required for distinct aspects of MTOC positioning, including centrosome separation, in the one cell stage Caenorhabditis elegans embryo. J Cell Biol 147: $135-150$. 
Gönczy P, Echeverri C, Oegema K, Coulson A, Jones SJ, Copley RR, Duperon J, Oegema J, Brehm M, Cassin E, et al. 2000. Functional genomic analysis of cell division in C. elegans using RNAi of genes on chromosome III. $\mathrm{Na}$ ture 408: 331-336.

Good MC, Vahey MD, Skandarajah A, Fletcher DA, Heald R. 2013. Cytoplasmic volume modulates spindle size during embryogenesis. Science 342: 856-860.

Goodwin SS, Vale RD. 2010. Patronin regulates the microtubule network by protecting microtubule minus ends. Cell 143: 263-274.

Goshima G, Vale RD. 2003. The roles of microtubule-based motor proteins in mitosis: Comprehensive RNAi analysis in the Drosophila S2 cell line. J Cell Biol 162: 1003-1016.

Goshima G, Wollman R, Stuurman N, Scholey JM, Vale RD. 2005. Length control of the metaphase spindle. Curr Biol 15: 1979-1988.

Goshima G, Wollman R, Goodwin SS, Zhang N, Scholey JM, Vale RD, Stuurman N. 2007. Genes required for mitotic spindle assembly in Drosophila S2 cells. Science 316: 417 421.

Goshima G, Mayer M, Zhang N, Stuurman N, Vale RD. 2008. Augmin: A protein complex required for centrosome-independent microtubule generation within the spindle. J Cell Biol 181: 421-429.

Greenan G, Brangwynne CP, Jaensch S, Gharakhani J, Jülicher F, Hyman AA. 2010. Centrosome size sets mitotic spindle length in Caenorhabditis elegans embryos. Curr Biol 20: 353-358.

Grill SW, Hyman AA. 2005. Spindle positioning by cortical pulling forces. Dev Cell 8: 461-465.

Gruss OJ, Vernos I. 2004. The mechanism of spindle assembly: Functions of Ran and its target TPX2. J Cell Biol 166: 949-955.

Gruss OJ, Carazo-Salas RE, Schatz CA, Guarguaglini G, Kast J, Wilm M, Le Bot N, Vernos I, Karsenti E, Mattaj IW. 2001. Ran induces spindle assembly by reversing the inhibitory effect of importin $\alpha$ on TPX2 activity. Cell 104: 83-93.

Gruss OJ, Wittmann M, Yokoyama H, Pepperkok R, Kufer T, Silljé H, Karsenti E, Mattaj IW, Vernos I. 2002. Chromosome-induced microtubule assembly mediated by TPX2 is required for spindle formation in HeLa cells. Nat Cell Biol 4: 871-879.

Hamill DR, Severson AF, Carter JC, Bowerman B. 2002. Centrosome maturation and mitotic spindle assembly in C. elegans require SPD-5, a protein with multiple coiled-coil domains. Dev Cell 3: 673-684.

Hannak E, Heald R. 2006. Xorbit/CLASP links dynamic microtubules to chromosomes in the Xenopus meiotic spindle. J Cell Biol 172: 19-25.

Hara Y, Kimura A. 2009. Cell-size-dependent spindle elongation in the Caenorhabditis elegans early embryo. Curr Biol 19: 1549-1554.

Hara Y, Kimura A. 2013. An allometric relationship between mitotic spindle width, spindle length, and ploidy in Caenorhabditis elegans embryos. Mol Biol Cell 24: 14111419.

Hartman JJ, Mahr J, McNally K, Okawa K, Iwamatsu A, Thomas S, Cheesman S, Heuser J, Vale RD, McNally FJ. 1998. Katanin, a microtubule-severing protein, is a novel
Emergent Properties of the Metaphase Spindle

AAA ATPase that targets to the centrosome using a WD40-containing subunit. Cell 93: 277-287.

Hazel J, Krutkramelis K, Mooney P, Tomschik M, Gerow K, Oakey J, Gatlin JC. 2013. Changes in cytoplasmic volume are sufficient to drive spindle scaling. Science 342: 853856.

Heald R, Tournebize R, Blank T, Sandaltzopoulos R, Becker P, Hyman A, Karsenti E. 1996. Self-organization of microtubules into bipolar spindles around artificial chromosomes in Xenopus egg extracts. Nature 382: 420-425.

Helenius J, Brouhard G, Kalaidzidis Y, Diez S, Howard J. 2006. The depolymerizing kinesin MCAK uses lattice diffusion to rapidly target microtubule ends. Nature 441: 115-119.

Hentrich C, Surrey T. 2010. Microtubule organization by the antagonistic mitotic motors kinesin-5 and kinesin-14. J Cell Biol 189: 465-480.

Hinchcliffe EH, Miller FJ, Cham M, Khodjakov A, Sluder G. 2001. Requirement of a centrosomal activity for cell cycle progression through $G_{1}$ into $S$ phase. Science 291: 15471550.

Honnappa S, Gouveia SM, Weisbrich A, Damberger FF, Bhavesh NS, Jawhari H, Grigoriev I, van Rijssel FJ, Buey RM, Lawera A, et al. 2009. An EB1-binding motif acts as a microtubule tip localization signal. Cell 138: 366-376.

Hotta T, Kong Z, Ho CM, Zeng CJ, Horio T, Fong S, Vuong T, Lee YR, Liu B. 2012. Characterization of the Arabidopsis augmin complex uncovers its critical function in the assembly of the acentrosomal spindle and phragmoplast microtubule arrays. Plant Cell 24: 1494-1509.

Howell BJ, McEwen BF, Canman JC, Hoffman DB, Farrar EM, Rieder CL, Salmon ED. 2001. Cytoplasmic dynein/ dynactin drives kinetochore protein transport to the spindle poles and has a role in mitotic spindle checkpoint inactivation. J Cell Biol 155: 1159-1172.

Hu CK, Coughlin M, Field CM, Mitchison TJ. 2011. KIF4 regulates midzone length during cytokinesis. Curr Biol 21: $815-824$.

Huang J, Roberts AJ, Leschziner AE, Reck-Peterson SL. 2012. Lis 1 acts as a "clutch" between the ATPase and microtubule-binding domains of the dynein motor. Cell 150: 975-986.

Hubner NC, Bird AW, Cox J, Splettstoesser B, Bandilla P, Poser I, Hyman A, Mann M. 2010. Quantitative proteomics combined with BAC TransgeneOmics reveals in vivo protein interactions. J Cell Biol 189: 739-754.

Hunter AW, Caplow M, Coy DL, Hancock WO, Diez S, Wordeman L, Howard J. 2003. The kinesin-related protein MCAK is a microtubule depolymerase that forms an ATP-hydrolyzing complex at microtubule ends. Mol Cell 11: $445-457$.

Hyman AA, Salser S, Drechsel DN, Unwin N, Mitchison TJ. 1992. Role of GTP hydrolysis in microtubule dynamics: Information from a slowly hydrolyzable analogue, GMPCPP. Mol Biol Cell 3: 1155-1167.

Itabashi T, Takagi J, Shimamoto Y, Onoe H, Kuwana K, Shimoyama I, Gaetz J, Kapoor TM, Ishiwata S. 2009 Probing the mechanical architecture of the vertebrate meiotic spindle. Nat Methods 6: 167-172.

Janson ME, Loughlin R, Loïodice I, Fu C, Brunner D, Nédélec FJ, Tran PT. 2007. Crosslinkers and motors organize 
dynamic microtubules to form stable bipolar arrays in fission yeast. Cell 128: 357-368.

Jiang K, Akhmanova A. 2011. Microtubule tip-interacting proteins: A view from both ends. Curr Opin Cell Biol 23: 94-101.

Kaláb P, Pu RT, Dasso M. 1999. The ran GTPase regulates mitotic spindle assembly. Curr Biol 9: 481-484.

Kaláb P, Weis K, Heald R. 2002. Visualization of a Ran-GTP gradient in interphase and mitotic Xenopus egg extracts. Science 295: 2452-2456.

Kaláb P, Pralle A, Isacoff EY, Heald R, Weis K. 2006. Analysis of a RanGTP-regulated gradient in mitotic somatic cells. Nature 440: 697-701.

Kamasaki T, O’Toole E, Kita S, Osumi M, Usukura J, McIntosh JR, Goshima G. 2013. Augmin-dependent microtubule nucleation at microtubule walls in the spindle. J Cell Biol 202: 25-33.

Kapitein LC, Janson ME, van den Wildenberg SM, Hoogenraad CC, Schmidt CF, Peterman EJ. 2008. Microtubuledriven multimerization recruits aselp onto overlapping microtubules. Curr Biol 18: 1713-1717.

Kapoor TM, Mayer TU, Coughlin ML, Mitchison TJ. 2000. Probing spindle assembly mechanisms with monastrol, a small molecule inhibitor of the mitotic kinesin, Eg5. J Cell Biol 150: 975-988.

Kardon JR, Vale RD. 2009. Regulators of the cytoplasmic dynein motor. Nat Rev Mol Cell Biol 10: 854-865.

Karsenti E, Nédélec F, Surrey T. 2006. Modelling microtubule patterns. Nat Cell Biol 8: 1204-1211.

Kashina AS, Baskin RJ, Cole DG, Wedaman KP, Saxton WM, Scholey JM. 1996. A bipolar kinesin. Nature 379: 270 272.

Keating TJ, Borisy GG. 2000. Immunostructural evidence for the template mechanism of microtubule nucleation. Nat Cell Biol 2: 352-357.

Khmelinskii A, Lawrence C, Roostalu J, Schiebel E. 2007. Cdc14-regulated midzone assembly controls anaphase B. J Cell Biol 177: 981-993.

Khodjakov A, Cole RW, Oakley BR, Rieder CL. 2000. Centrosome-independent mitotic spindle formation in vertebrates. Curr Biol 10: 59-67.

Khodjakov A, Copenagle L, Gordon MB, Compton DA, Kapoor TM. 2003. Minus-end capture of preformed kinetochore fibers contributes to spindle morphogenesis. $J$ Cell Biol 160: 671-683.

Kinoshita K, Arnal I, Desai A, Drechsel DN, Hyman AA. 2001. Reconstitution of physiological microtubule dynamics using purified components. Science 294: $1340-$ 1343.

Kiyomitsu T, Cheeseman IM. 2012. Chromosome- and spindle-pole-derived signals generate an intrinsic code for spindle position and orientation. Nat Cell Biol 14: 311-317.

Kollman JM, Polka JK, Zelter A, Davis TN, Agard DA. 2010. Microtubule nucleating $\gamma$-TuSC assembles structures with 13-fold microtubule-like symmetry. Nature 466: 879-882.

Komarova Y, De Groot CO, Grigoriev I, Gouveia SM, Munteanu EL, Schober JM, Honnappa S, Buey RM, Hoogenraad CC, Dogterom M, et al. 2009. Mammalian end bind- ing proteins control persistent microtubule growth. J Cell Biol 184: 691-706.

Kufer TA, Silljé HH, Körner R, Gruss OJ, Meraldi P, Nigg EA. 2002. Human TPX2 is required for targeting Aurora-A kinase to the spindle. J Cell Biol 158: 617-623.

Kumar P, Chimenti MS, Pemble H, Schönichen A, Thompson O, Jacobson MP, Wittmann T. 2012. Multisite phosphorylation disrupts arginine-glutamate salt bridge networks required for binding of cytoplasmic linkerassociated protein 2 (CLASP2) to end-binding protein 1 (EB1). J Biol Chem 287: 17050-17064.

Kurasawa Y, Earnshaw WC, Mochizuki Y, Dohmae N, Todokoro K. 2004. Essential roles of KIF4 and its binding partner PRC1 in organized central spindle midzone formation. EMBO J 23: 3237-3248.

Kwok BH, Yang JG, Kapoor TM. 2004. The rate of bipolar spindle assembly depends on the microtubule-gliding velocity of the mitotic kinesin Eg5. Curr Biol 14: 17831788.

Laan L, Pavin N, Husson J, Romet-Lemonne G, van Duijn M, López MP, Vale RD, Jülicher F, Reck-Peterson SL, Dogterom M. 2012. Cortical dynein controls microtubule dynamics to generate pulling forces that position microtubule asters. Cell 148: 502-514.

Lacroix B, van Dijk J, Gold ND, Guizetti J, Aldrian-Herrada G, Rogowski K, Gerlich DW, Janke C. 2010. Tubulin polyglutamylation stimulates spastin-mediated microtubule severing. J Cell Biol 189: 945-954.

Lawo S, Bashkurov M, Mullin M, Ferreria MG, Kittler R, Habermann B, Tagliaferro A, Poser I, Hutchins JR, Hegemann B, et al. 2009. HAUS, the 8-subunit human augmin complex, regulates centrosome and spindle integrity. Curr Biol 19: 816-826.

Leano JB, Rogers SL, Slep KC. 2013. A cryptic TOG domain with a distinct architecture underlies CLASP-dependent bipolar spindle formation. Structure 21: 939-950.

Leduc C, Padberg-Gehle K, Varga V, Helbing D, Diez S, Howard J. 2012. Molecular crowding creates traffic jams of kinesin motors on microtubules. Proc Natl Acad Sci 109: 6100-6105.

Lee MJ, Gergely F, Jeffers K, Peak-Chew SY, Raff JW. 2001. Msps/XMAP215 interacts with the centrosomal protein D-TACC to regulate microtubule behaviour. Nat Cell Biol 3: 643-649.

Levy DL, Heald R. 2012. Mechanisms of intracellular scaling. Annu Rev Cell Dev Biol 28: 113-135.

Libbrecht KG. 2005. The physics of snow crystals. Rep Prog Phys 68: 855-895.

Lombillo VA, Stewart RJ, McIntosh JR. 1995. Minus-enddirected motion of kinesin-coated microspheres driven by microtubule depolymerization. Nature 373: 161-164.

Loughlin R, Heald R, Nédélec F. 2010. A computational model predicts Xenopus meiotic spindle organization. $J$ Cell Biol 191: 1239-1249.

Loughlin R, Wilbur JD, McNally FJ, Nédélec FJ, Heald R. 2011. Katanin contributes to interspecies spindle length scaling in Xenopus. Cell 147: 1397-1407.

Mahoney NM, Goshima G, Douglass AD, Vale RD. 2006. Making microtubules and mitotic spindles in cells without functional centrosomes. Curr Biol 16: 564-569. 
Maiato H, Khodjakov A, Rieder CL. 2005. Drosophila CLASP is required for the incorporation of microtubule subunits into fluxing kinetochore fibres. Nat Cell Biol 7: $42-47$.

Manandhar G, Schatten H, Sutovsky P. 2005. Centrosome reduction during gametogenesis and its significance. Biol Reprod 72: 2-13.

Matthews LR, Carter P, Thierry-Mieg D, Kemphues K. 1998. ZYG-9, a Caenorhabditis elegans protein required for microtubule organization and function, is a component of meiotic and mitotic spindle poles. J Cell Biol 141: 11591168.

Matthies HJ, McDonald HB, Goldstein LS, Theurkauf WE. 1996. Anastral meiotic spindle morphogenesis: Role of the non-claret disjunctional kinesin-like protein. J Cell Biol 134: 455-464.

Maurer SP, Fourniol FJ, Bohner G, Moores CA, Surrey T. 2012. EBs recognize a nucleotide-dependent structural cap at growing microtubule ends. Cell 149: 371-382.

Mayer TU, Kapoor TM, Haggarty SJ, King RW, Schreiber SL, Mitchison TJ. 1999. Small molecule inhibitor of mitotic spindle bipolarity identified in a phenotype-based screen. Science 286: 971-974.

Mayr MI, Hümmer S, Bormann J, Grüner T, Adio S, Woehlke G, Mayer TU. 2007. The human kinesin Kif18A is a motile microtubule depolymerase essential for chromosome congression. Curr Biol 17: 488-498.

McNally FJ, Vale RD. 1993. Identification of katanin, an ATPase that severs and disassembles stable microtubules. Cell 75: 419-429.

McNally K, Audhya A, Oegema K, McNally FJ. 2006. Katanin controls mitotic and meiotic spindle length. J Cell Biol 175: 881-891.

Megraw TL, Kao LR, Kaufman TC. 2001. Zygotic development without functional mitotic centrosomes. Curr Biol 11: $116-120$.

Meng W, Mushika Y, Ichii T, Takeichi M. 2008. Anchorage of microtubule minus ends to adherens junctions regulates epithelial cell-cell contacts. Cell 135: 948-959.

Mennella V, Rogers GC, Rogers SL, Buster DW, Vale RD, Sharp DJ. 2005. Functionally distinct kinesin-13 family members cooperate to regulate microtubule dynamics during interphase. Nat Cell Biol 7: 235-245.

Merdes A, Ramyar K, Vechio JD, Cleveland DW. 1996. A complex of NuMA and cytoplasmic dynein is essential for mitotic spindle assembly. Cell 87: 447-458.

Meunier S, Vernos I. 2011. K-fibre minus ends are stabilized by a RanGTP-dependent mechanism essential for functional spindle assembly. Nat Cell Biol 13: 1406-1414.

Mimori-Kiyosue Y, Grigoriev I, Lansbergen G, Sasaki H, Matsui C, Severin F, Galjart N, Grosveld F, Vorobjev I, Tsukita S, et al. 2005. CLASP1 and CLASP2 bind to EB1 and regulate microtubule plus-end dynamics at the cell cortex. J Cell Biol 168: 141-153.

Mitchison TJ. 1993. Localization of an exchangeable GTP binding site at the plus end of microtubules. Science 261: 1044-1047.

Mitchison TJ and Kirschner M. 1984. Dynamic instability of microtubule growth. Nature 312: 237-242.

Mitchison TJ, Maddox P, Gaetz J, Groen A, Shirasu M, Desai A, Salmon ED, Kapoor TM. 2005. Roles of polymeriza-
Emergent Properties of the Metaphase Spindle

tion dynamics, opposed motors, and a tensile element in governing the length of Xenopus extract meiotic spindles. Mol Biol Cell 16: 3064-3076.

Mollinari C, Kleman JP, Jiang W, Schoehn G, Hunter T, Margolis RL. 2002. PRC1 is a microtubule binding and bundling protein essential to maintain the mitotic spindle midzone. J Cell Biol 157: 1175-1186.

Montorzi M, Burgos MH, Falchuk KH. 2000. Xenopus laevis embryo development: Arrest of epidermal cell differentiation by the chelating agent 1,10-phenanthroline. Mol Reprod Dev 55: 75-82.

Moritz M, Braunfeld MB, Sedat JW, Alberts B, Agard DA. 1995. Microtubule nucleation by $\gamma$-tubulin-containing rings in the centrosome. Nature 378: 638-640.

Moritz M, Braunfeld MB, Guénebaut V, Heuser J, Agard DA. 2000. Structure of the $\gamma$-tubulin ring complex: A template for microtubule nucleation. Nat Cell Biol 2: 365370 .

Mountain V, Simerly C, Howard L, Ando A, Schatten G, Compton DA. 1999. The kinesin-related protein, HSET, opposes the activity of Eg5 and cross-links microtubules in the mammalian mitotic spindle. J Cell Biol 147: 351366.

Nachury MV, Maresca TJ, Salmon WC, Waterman-Storer CM, Heald R, Weis K. 2001. Importin $\beta$ is a mitotic target of the small GTPase Ran in spindle assembly. Cell 104: 95-106.

Nakaoka Y, Miki T, Fujioka R, Uehara R, Tomioka A, Obuse C, Kubo M, Hiwatashi Y, Goshima G. 2012. An inducible RNA interference system in Physcomitrella patens reveals a dominant role of augmin in phragmoplast microtubule generation. Plant Cell 24: 1478-1493.

Needlemann DJ, Groen A, Ohi R, Maresca T, Mirny L, Mitchison T. 2010. Fast microtubule dynamics in meiotic spindles measured by single molecule imaging: Evidence that the spindle environment does not stabilize microtubules. Mol Biol Cell 21: 323-333.

Norrander JM, Linck RW, Stephens RE. 1995. Transcriptional control of tektin A mRNA correlates with cilia development and length determination during sea urchin embryogenesis. Development 121: 1615-1623.

Oguchi Y, Uchimura S, Ohki T, Mikhailenko SV, Ishiwata S. 2011. The bidirectional depolymerizer MCAK generates force by disassembling both microtubule ends. Nat Cell Biol 13: 846-852.

Ohba T, Nakamura M, Nishitani H, Nishimoto T. 1999. Selforganization of microtubule asters induced in Xenopus egg extracts by GTP-bound Ran. Science 284: 1356-1358.

Ozlü N, Srayko M, Kinoshita K, Habermann B, O’Toole ET, Müller-Reichert T, Schmalz N, Desai A, Hyman AA 2005. An essential function of the C. elegans ortholog of TPX2 is to localize activated Aurora A kinase to mitotic spindles. Dev Cell 9: 237-248.

Pereira G, Schiebel E. 1997. Centrosome-microtubule nucleation. J Cell Sci 110: 295-300.

Pereira AL, Pereira AJ, Maia AR, Drabek K, Sayas CL, Hergert PJ, Lince-Faria M, Matos I, Duque C, Stepanova T, et al. 2006. Mammalian CLASP1 and CLASP2 cooperate to ensure mitotic fidelity by regulating spindle and kinetochore function. Mol Biol Cell 17: 4526-4542. 
Peset I, Vernos I. 2008. The TACC proteins: TACC-ling microtubule dynamics and centrosome function. Trends Cell Biol 18: 379-388.

Petry S, Pugieux C, Nédélec FJ, Vale RD. 2011. Augmin promotes meiotic spindle formation and bipolarity in Xenopus egg extracts. Proc Natl Acad Sci 108: 1447314478.

Petry S, Groen AC, Ishihara K, Mitchison TJ, Vale RD. 2013. Branching microtubule nucleation in Xenopus egg extracts mediated by augmin and TPX2. Cell 312: 237-242.

Pfarr CM, Coue M, Grissom PM, Hays TS, Porter ME, McIntosh JR. 1990. Cytoplasmic dynein is localized to kinetochores during mitosis. Nature 345: 263-265.

Rai AK, Rai A, Ramaiya AJ, Jha R, Mallik R. 2013. Molecular adaptations allow dynein to generate large collective forces inside cells. Cell 152: 172-182.

Rankin KE, Wordeman L. 2010. Long astral microtubules uncouple mitotic spindles from the cytokinetic furrow. $J$ Cell Biol 190: 35-43.

Reber S, Baumgart J, Widlund PO, Pozniakovsky A, Howard J, Hyman AA, Jülicher F. 2013. XMAP215 activity sets spindle length by controlling the total mass of spindle microtubules. Nat Cell Biol 15: 1116-1122.

Rogers GC, Rogers SL, Schwimmer TA, Ems-McClung SC, Walczak CE, Vale RD, Scholey JM, Sharp DJ. 2004. Two mitotic kinesins cooperate to drive sister chromatid separation during anaphase. Nature 427: 364-370.

Roostalu J, Surrey T. 2013. The multiple talents of kinesin- 8 . Nat Cell Biol 15: 889-891.

Sato M, Toda T. 2007. Alp7/TACC is a crucial target in RanGTPase-dependent spindle formation in fission yeast. Nature 447: 334-337.

Saunders W, Lengyel V, Hoyt MA. 1997. Mitotic spindle function in Saccharomyces cerevisiae requires a balance between different types of kinesin-related motors. $\mathrm{Mol}$ Biol Cell 8: 1025-1033.

Saunders AM, Powers J, Strome S, Saxton WM. 2007. Kine$\sin -5$ acts as a brake in anaphase spindle elongation. Curr Biol 17: R453-R454.

Savoian MS, Glover DM. 2010. Drosophila Klp67A binds prophase kinetochores to subsequently regulate congression and spindle length. J Cell Sci 123: 767-776.

Schatz CA, Santarella R, Hoenger A, Karsenti E, Mattaj IW, Gruss OJ, Carazo-Salas RE. 2003. Importin $\alpha$-regulated nucleation of microtubules by TPX2. EMBO J 22: 2060 2070.

Schimizzi GV, Currie JD, Rogers SL. 2010. Expression levels of a kinesin-13 microtubule depolymerase modulates the effectiveness of anti-microtubule agents. PLOS ONE 5: el1381.

Scolz M, Widlund PO, Piazza S, Bublik DR, Reber S, Peche LY, Ciani Y, Hubner N, Isokane M, Monte M, et al. 2012. GTSE1 is a microtubule plus-end tracking protein that regulates EB1-dependent cell migration. PLOS ONE 7: e51259.

Sharma N, Bryant J, Wloga D, Donaldson R, Davis RC, Jerka-Dziadosz M, Gaertig J. 2007. Katanin regulates dynamics of microtubules and biogenesis of motile cilia. $J$ Cell Biol 178: 1065-1079.

Sharp DJ, Yu KR, Sisson JC, Sullivan W, Scholey JM. 1999a. Antagonistic microtubule-sliding motors position mi- totic centrosomes in Drosophila early embryos. Nat Cell Biol 1: 51-54.

Sharp DJ, McDonald KL, Brown HM, Matthies HJ, Walczak C, Vale RD, Mitchison TJ, Scholey JM. 1999b. The bipolar kinesin, KLP61F, cross-links microtubules within interpolar microtubule bundles of Drosophila embryonic mitotic spindles. J Cell Biol 144: 125-138.

Sharp DJ, Roger GC, Scholey JM. 2000. Microtubule motors in mitosis. Nature 407: 41-47.

Shimamoto Y, Maeda YT, Ishiwata S, Libchaber AJ, Kapoor TM. 2011. Insights into the micromechanical properties of the metaphase spindle. Cell 145: 1062-1074.

Sivaram MV, Wadzinski TL, Redick SD, Manna T, Doxsey SJ. 2009. Dynein light intermediate chain 1 is required for progress through the spindle assembly checkpoint. EMBO J 28: 902-914.

Sköld HN, Komma DJ, Endow SA. 2005. Assembly pathway of the anastral Drosophila oocyte meiosis I spindle. J Cell Sci 118: 1745-1755.

Sousa A, Reis R, Sampaio P, Sunkel CE. 2007. The Drosophila CLASP homologue, Mast/Orbit regulates the dynamic behaviour of interphase microtubules by promoting the pause state. Cell Motil Cytoskeleton 64: 605-620.

Splinter D, Tanenbaum ME, Lindqvist A, Jaarsma D, Flotho A, Yu KL, Grigoriev I, Engelsma D, Haasdijk ED, Keijzer N, et al. 2010. Bicaudal D2, dynein, and kinesin-1 associate with nuclear pore complexes and regulate centrosome and nuclear positioning during mitotic entry. PLoS Biol 8: e1000350.

Srayko M, Buster DW, Bazirgan OA, McNally FJ, Mains PE. 2000. MEI-1/MEI-2 katanin-like microtubule severing activity is required for Caenorhabditis elegans meiosis. Genes Dev 14: 1072-1084.

Srayko M, O’Toole ET, Hyman AA, Müller-Reichert T. 2006. Katanin disrupts the microtubule lattice and increases polymer number in C. elegans meiosis. Curr Biol 16: 1944-1949.

Stephens RE. 1989. Quantal tektin synthesis and ciliary length in sea-urchin embryos. J Cell Sci 92: 403-413.

Steuer ER, Wordeman L, Schroer TA, Sheetz MP. 1990. Localization of cytoplasmic dynein to mitotic spindles and kinetochores. Nature 345: 266-268.

Stout JR, Yount AL, Powers JA, Leblanc C, Ems-McClung SC, Walczak CE. 2011. Kif18B interacts with EB1 and controls astral microtubule length during mitosis. Mol Biol Cell 22: 3070-3080.

Stumpff J, von Dassow G, Wagenbach M, Asbury C, Wordeman L. 2008. The kinesin-8 motor Kif18A suppresses kinetochore movements to control mitotic chromosome alignment. Dev Cell 14: 252-262.

Subramanian R, Kapoor TM. 2012. Building complexity: Insights into self-organized assembly of microtubulebased architectures. Dev Cell 23: 874-885.

Subramanian R, Wilson-Kubalek EM, Arthur CP, Bick MJ, Campbell EA, Darst SA, Milligan RA, Kapoor TM. 2010. Insights into antiparallel microtubule crosslinking by PRC1, a conserved nonmotor microtubule binding protein. Cell 142: 433-443.

Subramanian R, Ti SC, Tan L, Darst SA, Kapoor TM. 2013. Marking and measuring single microtubules by PRC1 and kinesin-4. Cell 154: 377-390. 
Tanenbaum ME, Medema RH. 2010. Mechanisms of centrosome separation and bipolar spindle assembly. Dev Cell 19: 797-806.

Tanenbaum ME, Macůrek L, Galjart N, Medema RH. 2008. Dynein, Lis1 and CLIP-170 counteract Eg5-dependent centrosome separation during bipolar spindle assembly. EMBO J 27: 3235-3245.

Tanenbaum ME, Medema RH, Akhmanova A. 2011. Regulation of localization and activity of the microtubule depolymerase MCAK. Bioarchitecture 1: 80-87.

Tao L, Mogilner A, Civelekoglu-Scholey G, Wollman R, Evans J, Stahlberg H, Scholey JM. 2006. A homotetrameric kinesin-5, KLP61F, bundles microtubules and antagonizes Ncd in motility assays. Curr Biol 16: 2293-2302.

Tournebize R, Popov A, Kinoshita K, Ashford AJ, Rybina S, Pozniakovsky A, Mayer TU, Walczak CE, Karsenti E, Hyman AA. 2000. Control of microtubule dynamics by the antagonistic activities of XMAP215 and XKCM1 in Xenopus egg extracts. Nat Cell Biol 2: 13-19.

Trokter M, Mücke N, Surrey T. 2012. Reconstitution of the human cytoplasmic dynein complex. Proc Natl Acad Sci 109: 20895-20900.

Tsai MY, Wiese C, Cao K, Martin O, Donovan P, Ruderman J, Prigent C, Zheng Y. 2003. A Ran signalling pathway mediated by the mitotic kinase Aurora A in spindle assembly. Nat Cell Biol 5: 242-248.

Tulu US, Fagerstrom C, Ferenz NP, Wadsworth P. 2006. Molecular requirements for kinetochore-associated microtubule formation in mammalian cells. Curr Biol 16: 536541.

Uehara R, Goshima G. 2010. Functional central spindle assembly requires de novo microtubule generation in the interchromosomal region during anaphase. J Cell Biol 191: $259-267$.

Uehara R, Nozawa RS, Tomioka A, Petry S, Vale RD, Obuse C, Goshima G. 2009. The augmin complex plays a critical role in spindle microtubule generation for mitotic progression and cytokinesis in human cells. Proc Natl Acad Sci 106: 6998-7003.

Uteng M, Hentrich C, Miura K, Bieling P, Surrey T. 2008. Poleward transport of Eg5 by dynein-dynactin in Xenopus laevis egg extract spindles. J Cell Biol 182: 715-726.

Vaisberg EA, Koonce MP, McIntosh JR. 1993. Cytoplasmic dynein plays a role in mammalian mitotic spindle formation. J Cell Biol 123: 849-858.

Vale RD. 1991. Severing of stable microtubules by a mitotically activated protein in Xenopus egg extracts. Cell 64: 827-839.

Vale RD, Malik F, Brown D. 1992. Directional instability of microtubule transport in the presence of kinesin and dynein, two opposite polarity motor proteins. J Cell Biol 119: 1589-1596.

van Breugel M, Drechsel D, Hyman A. 2003. Stu2p, the budding yeast member of the conserved Dis1/ XMAP215 family of microtubule-associated proteins is a plus end-binding microtubule destabilizer. J Cell Biol 161: 359-369.

van der Vaart B, Manatschal C, Grigoriev I, Olieric V, Gouveia SM, Bjelic S, Demmers J, Vorobjev I, Hoogenraad CC, Steinmetz MO, et al. 2011. SLAIN2 links microtu-
Emergent Properties of the Metaphase Spindle

bule plus end-tracking proteins and controls microtubule growth in interphase. J Cell Biol 193: 1083-1099.

Varga V, Helenius J, Tanaka K, Hyman AA, Tanaka TU, Howard J. 2006. Yeast kinesin-8 depolymerizes microtubules in a length-dependent manner. Nat Cell Biol 8: 957-962.

Varga V, Leduc C, Bormuth V, Diez S, Howard J. 2009. Kinesin-8 motors act cooperatively to mediate lengthdependent microtubule depolymerization. Cell 138: 1174-1183.

Varma D, Monzo P, Stehman SA, Vallee RB. 2008. Direct role of dynein motor in stable kinetochore-microtubule attachment, orientation, and alignment. J Cell Biol 182: 1045-1054.

Walczak CE, Mitchison TJ, Desai A. 1996. XKCM1: A Xenopus kinesin-related protein that regulates microtubule dynamics during mitotic spindle assembly. Cell 84: $37-$ 47.

Walker RA, O'Brien ET, Pryer NK, Soboeiro MF, Voter WA, Erickson HP, Salmon ED. 1988. Dynamic instability of individual microtubules analyzed by video light microscopy: Rate constants and transition frequencies. J Cell Biol 107: 1437-1448.

Wang H, Brust-Mascher I, Civelekoglu-Scholey G, Scholey JM. 2013. Patronin mediates a switch from kinesin-13dependent poleward flux to anaphase B spindle elongation. J Cell Biol 203: 35-46.

West RR, Malmstrom T, Troxell CL, McIntosh JR. 2001. Two related kinesins, $\mathrm{klp5}^{+}$and $\mathrm{klp}^{+}$, foster microtubule disassembly and are required for meiosis in fission yeast. Mol Biol Cell 12: 3919-3932.

Widlund PO, Stear JH, Pozniakovsky A, Zanic M, Reber S, Brouhard GJ, Hyman AA, Howard J. 2011. XMAP215 polymerase activity is built by combining multiple tubulin-binding TOG domains and a basic lattice-binding region. Proc Natl Acad Sci 108: 2741-2746.

Wiese C, Zheng Y. 2000. A new function for the $\gamma$-tubulin ring complex as a microtubule minus-end cap. Nat Cell Biol 2: 358-364.

Wiese C, Zheng Y. 2006. Microtubule nucleation: $\gamma$-Tubulin and beyond. J Cell Sci 119: 4143-4153.

Wilbur JD, Heald R. 2013a. Cryptic no longer: Arrays of CLASP1 TOG domains. Structure 21: 869-870.

Wilbur JD, Heald R. 2013b. Mitotic spindle scaling during Xenopus development by kif2a and importin $\alpha$. eLife 2: e00290.

Wittmann T, Wilm M, Karsenti E, Vernos I. 2000. TPX2, A novel Xenopus MAP involved in spindle pole organization. J Cell Biol 149: 1405-1418.

Wollman R, Civelekoglu-Scholey G, Scholey JM, Mogilner A. 2008. Reverse engineering of force integration during mitosis in the Drosophila embryo. Mol Syst Biol 4: 195.

Wühr M, Chen Y, Dumont S, Groen AC, Needleman DJ, Salic A, Mitchison TJ. 2008. Evidence for an upper limit to mitotic spindle length. Curr Biol 18: 1256-1261.

Wühr M, Tan ES, Parker SK, Detrich HW, Mitchison TJ. 2010. A model for cleavage plane determination in early amphibian and fish embryos. Curr Biol 20: 2040 2045. 
S. Reber and A.A. Hyman

Yang G, Houghtaling BR, Gaetz J, Liu JZ, Danuser G, Kapoor TM. 2007. Architectural dynamics of the meiotic spindle revealed by single-fluorophore imaging. Nat Cell Biol 9: 1233-1242.

Yu W, Qiang L, Solowska JM, Karabay A, Korulu S, Baas PW 2008. The microtubule-severing proteins spastin and katanin participate differently in the formation of axonal branches. Mol Biol Cell 19: 1485-1498.

Zanic M, Stear JH, Hyman AA, Howard J. 2009. EB1 recognizes the nucleotide state of tubulin in the microtubule lattice. PLoS ONE 4: e7585.

Zanic M, Widlund PO, Hyman AA, Howard J. 2013. Synergy between XMAP215 and EB1 increases microtubule growth rates to physiological levels. Nat Cell Biol 15: 688-693.

Zhang H, Dawe RK. 2011. Mechanisms of plant spindle formation. Chromosome Res 19: 335-344.
Zhang D, Rogers GC, Buster DW, Sharp DJ. 2007. Three microtubule severing enzymes contribute to the "Pacman-flux" machinery that moves chromosomes. J Cell Biol 177: 231-242.

Zhang D, Grode KD, Stewman SF, Diaz-Valencia JD, Liebling E, Rath U, Riera T, Currie JD, Buster DW, Asenjo AB, et al. 2011. Drosophila katanin is a microtubule depolymerase that regulates cortical-microtubule plus-end interactions and cell migration. Nat Cell Biol 13: $361-$ 370.

Zheng Y, Wong ML, Alberts B, Mitchison T. 1995. Nucleation of microtubule assembly by a $\gamma$-tubulin-containing ring complex. Nature 378: 578-583.

Zhu H, Coppinger JA, Jang CY, Yates JR III, Fang G. 2008. FAM29A promotes microtubule amplification via recruitment of the NEDD1- $\gamma$-tubulin complex to the mitotic spindle. J Cell Biol 183: 835-848. 


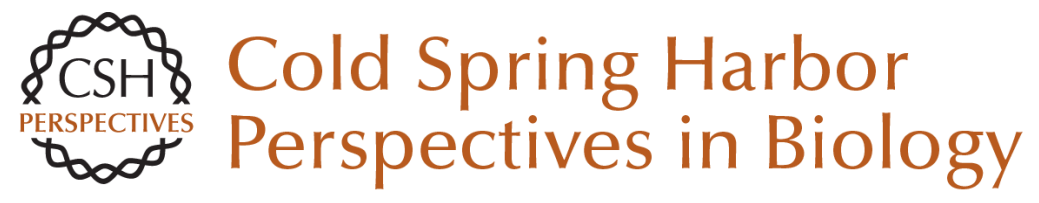

\section{Emergent Properties of the Metaphase Spindle}

Simone Reber and Anthony A. Hyman

Cold Spring Harb Perspect Biol 2015; doi: 10.1101/cshperspect.a015784

Subject Collection Mitosis

Emergent Properties of the Metaphase Spindle Simone Reber and Anthony A. Hyman

Meiosis: An Overview of Key Differences from Mitosis Hiroyuki Ohkura

Cytokinesis in Animal Cells

Pier Paolo D'Avino, Maria Grazia Giansanti and Mark Petronczki

The Centrosome and Its Duplication Cycle Jingyan Fu, lain M. Hagan and David M. Glover

The Role of Model Organisms in the History of Mitosis Research Mitsuhiro Yanagida
Chromosome Dynamics during Mitosis Tatsuya Hirano

The Centromere: Epigenetic Control of Chromosome Segregation during Mitosis Frederick G. Westhorpe and Aaron F. Straight

The Biochemistry of Mitosis Samuel Wieser and Jonathon Pines

Aurea Mediocritas: The Importance of a Balanced Genome

Gianluca Varetti, David Pellman and David J. Gordon

The Kinetochore lain M. Cheeseman

For additional articles in this collection, see http://cshperspectives.cshlp.org/cgi/collection/

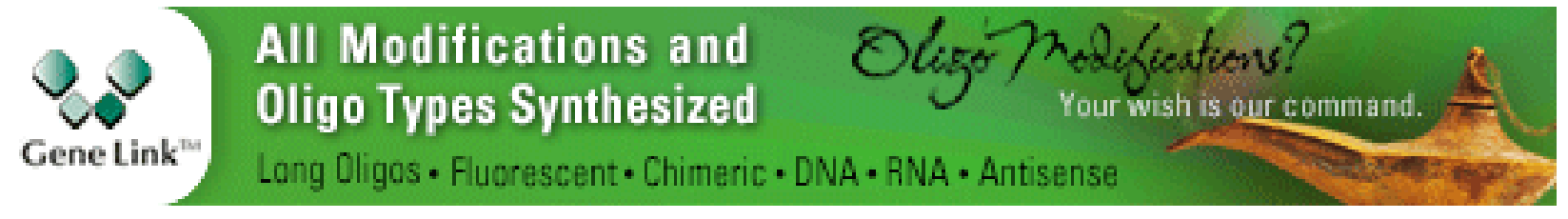

Copyright @ 2015 Cold Spring Harbor Laboratory Press; all rights reserved 